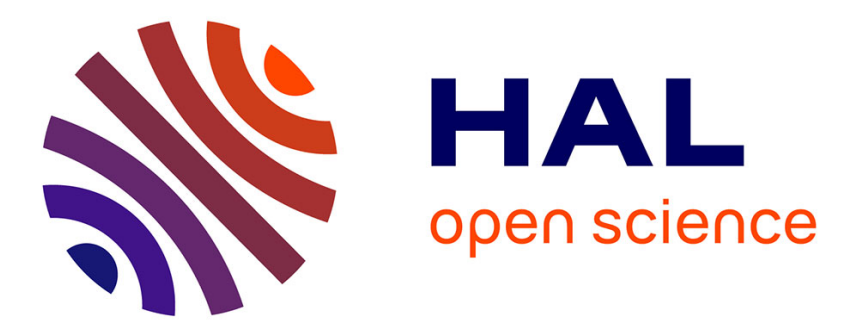

\title{
Photoionization spectroscopy of CH3C3N in the vacuum-ultraviolet range
}

\author{
N. Lamarre, C. Falvo, C. Alcaraz, B. Cunha de Miranda, S. Douin, A.
} Flütsch, C. Romanzin, J.-C. Guillemin, Séverine Boyé-Péronne, B. Gans

\section{- To cite this version:}

N. Lamarre, C. Falvo, C. Alcaraz, B. Cunha de Miranda, S. Douin, et al.. Photoionization spectroscopy of CH3C3N in the vacuum-ultraviolet range. Journal of Molecular Spectroscopy, 2015, 315, pp.206216. 10.1016/j.jms.2015.03.005 . hal-01138635

\section{HAL Id: hal-01138635 \\ https://hal-univ-rennes1.archives-ouvertes.fr/hal-01138635}

Submitted on 4 Nov 2015

HAL is a multi-disciplinary open access archive for the deposit and dissemination of scientific research documents, whether they are published or not. The documents may come from teaching and research institutions in France or abroad, or from public or private research centers.
L'archive ouverte pluridisciplinaire HAL, est destinée au dépôt et à la diffusion de documents scientifiques de niveau recherche, publiés ou non, émanant des établissements d'enseignement et de recherche français ou étrangers, des laboratoires publics ou privés. 


\title{
Photoionization spectroscopy of $\mathrm{CH}_{3} \mathrm{C}_{3} \mathrm{~N}$ in the vacuum-ultraviolet range
}

\author{
N. Lamarre ${ }^{\mathrm{a}}$, C. Falvo ${ }^{\mathrm{a}}$, C. Alcaraz ${ }^{\text {b,c }}$, B. Cunha de Miranda ${ }^{\mathrm{b}}$, S. Douin ${ }^{\mathrm{a}}$, A. Flütsch ${ }^{\mathrm{a}}$, C. Romanzin ${ }^{\mathrm{b}}$, J.-C. Guillemin ${ }^{\mathrm{d}}$, \\ S. Boyé-Péronne $e^{\mathrm{a}, *}$, B. Gans ${ }^{\mathrm{a}, *}$ \\ anstitut des Sciences Moléculaires d'Orsay, Univ Paris-Sud; CNRS, bat 210, Univ Paris-Sud 91405 Orsay cedex (France) \\ ${ }^{b}$ Laboratoire de Chimie Physique, Univ Paris-Sud; CNRS UMR 8000, bat 350, Univ Paris-Sud 91405 Orsay cedex (France) \\ ${ }^{c}$ Synchrotron SOLEIL, L'Orme des Merisiers, St. Aubin, B.P. 48, 91192, Gif-sur-Yvette cedex, (France) \\ ${ }^{d}$ Institut des Sciences Chimiques de Rennes, École Nationale Supérieure de Chimie de Rennes, CNRS UMR 6226, 35708 Rennes cedex 7, (France)
}

\begin{abstract}
Using vacuum-ultraviolet (VUV) synchrotron radiation, threshold and dissociative photoionization of cyanopropyne $\left(\mathrm{CH}_{3} \mathrm{C}_{3} \mathrm{~N}\right)$ in the gas phase have been studied from $86000 \mathrm{~cm}^{-1}$ up to $180000 \mathrm{~cm}^{-1}$ by recording Threshold-PhotoElectron Spectrum (TPES) and PhotoIon Yield (PIY). Ionization energies of the four lowest electronic states $\tilde{\mathrm{X}}^{+2} \mathrm{E}, \tilde{\mathrm{A}}^{+2} \mathrm{~A}_{1}, \tilde{\mathrm{B}}^{+2} \mathrm{E}$ and $\tilde{\mathrm{C}}^{+}$of $\mathrm{CH}_{3} \mathrm{C}_{3} \mathrm{~N}^{+}$are derived from the TPES with a better accuracy than previously reported. The adiabatic ionization potential of $\mathrm{CH}_{3} \mathrm{C}_{3} \mathrm{~N}$ is measured as $86872 \pm 20 \mathrm{~cm}^{-1}$. A description of the vibrational structure of these states is proposed leading to the first determination of the vibrational frequencies for most modes. The vibrational assignments of the $\tilde{X}^{+}$state are supported by density functional theory calculations. In addition, dissociative photoionization spectra have been recorded for several cationic fragments in the range 12$15.5 \mathrm{eV}$ (96790-125000 $\mathrm{cm}^{-1}$ ) and they bring new information on the photophysics of $\mathrm{CH}_{3} \mathrm{C}_{3} \mathrm{~N}^{+}$. Threshold energies for the cationic dissociative channels leading to $\mathrm{CH}_{2} \mathrm{C}_{3} \mathrm{~N}^{+}, \mathrm{CHC}_{3} \mathrm{~N}^{+}, \mathrm{HC}_{3} \mathrm{H}^{+}, \mathrm{HCNH}^{+}$and $\mathrm{CH}_{3}^{+}$have been measured for the first time and are compared with quantum chemical calculations.
\end{abstract}

Keywords: cyanopropyne, methylcyanoacetylene, 2-butynenitrile, $\mathrm{CH}_{3} \mathrm{C}_{3} \mathrm{~N}$, synchrotron radiation, TPES, dissociative photoionization, DFT calculations

\section{Introduction}

Cyanopropyne $\mathrm{CH}_{3}-\mathrm{C} \equiv \mathrm{C}-\mathrm{C} \equiv \mathrm{N}$ (or 2-butynenitrile) is the methylated derivative of cyanoacetylene $\mathrm{HC}_{3} \mathrm{~N}$, an important astrophysical species. Although the chemical and physical properties of $\mathrm{HC}_{3} \mathrm{~N}$ have been extensively studied (see for instance Ref. [1] and references therein), cyanopropyne has been much less investigated. Less ubiquitous than $\mathrm{HC}_{3} \mathrm{~N}$, which has been observed in several molecular clouds of the Interstellar Medium (ISM), in Titan and in comets, cyanopropyne was detected in 1984 in the molecular cloud TMC-1 and more recently in Sgr B2 [2,3]. Twelve years after its first detection, an isomer, the cyanoallene (2,3-butadienenitrile, $\mathrm{H}_{2} \mathrm{C}=\mathrm{C}=\mathrm{CHCN}$ ) was found in TMC-1 [4] but in lower amounts: a 0.25 ratio compared to cyanopropyne, as it has been often observed for thermodynamically less stable compounds [5].

Even if it has never been unambiguously detected up to now in the atmosphere of Titan, the presence of cyanopropyne was found in several atmosphere simulations of this satellite using a plasma discharge in $\mathrm{N}_{2}-\mathrm{CH}_{4}$ mixtures at low pressures [6, 7 , 8]. Note that Vuitton et al. reported the detection of a $\mathrm{C}_{4} \mathrm{H}_{3} \mathrm{~N}$ species in the atmosphere of Titan by mass spectrometry [9] but did not specify the corresponding molecular structure.

To explain its formation in the ISM as well as how it could be formed in the atmosphere of Titan, the addition of the $\mathrm{CN}$

\footnotetext{
*corresponding authors: berenger.gans@u-psud.fr; severine.boyeperonne@u-psud.fr
}

radical on propyne (a gas observed in the ISM as well as in the atmosphere of Titan) has been proposed. Corresponding studies have been performed via a neutral-neutral reaction under single collision conditions in a crossed molecular beam experiment to yield the expected product and the cyanoallene isomer [10, 11, 12]. However other approaches starting from cyanoacetylene might also be proposed for its synthesis in these media.

Cyanopropyne is a prolate symmetric top which has a neutral ground state configuration [core] $\left(1 \mathrm{a}_{1}\right)^{2}\left(2 \mathrm{a}_{1}\right)^{2}\left(3 \mathrm{a}_{1}\right)^{2}\left(4 \mathrm{a}_{1}\right)^{2}\left(5 \mathrm{a}_{1}\right)^{2}(1 \mathrm{e})^{4}(2 \mathrm{e})^{4}\left(6 \mathrm{a}_{1}\right)^{2}(3 \mathrm{e})^{4}$, leading to a $\tilde{\mathrm{X}}{ }^{1} \mathrm{~A}_{1}$ state in the $\mathrm{C}_{3 \mathrm{v}}$ point group. This molecule has 12 vibrational modes: 6 symmetric modes of $\mathrm{a}_{1}$ symmetry $\left(v_{1}\right.$ to $\left.v_{6}\right)$ and 6 degenerate modes of e symmetry $\left(v_{7}\right.$ to $\left.v_{12}\right)$. The vibrational structure of the electronic ground state has been studied by infrared spectroscopy $[13,14,15]$. The rotational structure of the vibronic ground state $[16,17,18]$ and of the $v_{12}$ fundamental vibrational level [19] have also been determined by microwave spectroscopy.

Concerning the electronic spectroscopy of cyanopropyne, Bruston et al. recorded a UV absorption spectrum at roomtemperature between 185 and $250 \mathrm{~nm}$ and made the first vibronic analysis of the transition to the first valence state [20]. On the other hand, the highly-excited electronic stucture is still to be unveiled since no vacuum-ultraviolet (VUV) absorption nor multiphoton excitation spectra of $\mathrm{CH}_{3}-\mathrm{C} \equiv \mathrm{C}-\mathrm{C} \equiv \mathrm{N}$ have been reported to date.

As for the cyanopropyne cation, very little information is cur- 
rently available. This information has been obtained by $\mathrm{He}(\mathrm{I})$ and $\mathrm{He}(\mathrm{II})$ photoelectron spectroscopy [21, 22, 23] in the gas phase or by neon matrix absorption spectroscopy [24]. From these studies, ionization energies of the six lowest electronic states have been extracted and only a few vibrational frequencies of the three lowest electronic states of the cation have been measured with consequent error bars.

Finally, only three theoretical studies have been reported to our knowledge: in 1982, Niessen et al. calculated ionization energies of $\mathrm{CH}_{3} \mathrm{C}_{3} \mathrm{~N}$ by a Green's function method [25], in the 90's Siam et al. optimized the geometry of the neutral species using Hartree-Fock calculations [26] and Moliner et al. obtained the rotational constant and the dipole moment of the vibronic ground state with second-order-Møller-Plesset (MP2) and density-functional-theory (DFT) calculations [27].

The present work is focused on the $\mathrm{CH}_{3}-\mathrm{C} \equiv \mathrm{C}-\mathrm{C} \equiv \mathrm{N}$ cationic species which might be involved in the ion-neutral chemistry of astrophysical media, as for instance the ISM and the upper atmosphere of Titan. The first part of this paper is devoted to an accurate description of the vibronic structure of the cation reached by direct ionization from the neutral ground state. Vibrational assignment of the $\tilde{\mathrm{X}}^{+}$spectrum is guided by exploratory density functional theory (DFT) calculations. In the second part of this paper, dissociative ionization is studied through observation of appearance energies for the different cationic fragmentation channels of $\mathrm{CH}_{3} \mathrm{C}_{3} \mathrm{~N}^{+}$. They are compared with estimated thresholds obtained by DFT calculations.

\section{Experiment}

2-Butynenitrile (cyanopropyne) has been prepared in a twostep sequence starting from ethyl butynoate (Alfa-aesar) used as a precursor of 2-butynamide, as previously reported [28]. Then, in a flask under nitrogen, 2-butynamide (5g, $60 \mathrm{mmol})$ was mixed with sea sand $(30 \mathrm{~g})$ and phosphorus pentoxide (33.8 g, $240 \mathrm{mmol})$. The flask was fitted on a vacuum line (0.1 mbar) equipped with two traps. The first one was immersed in a bath cooled at $-10^{\circ} \mathrm{C}$ (to trap the high boiling-temperature impurities) and the second one in a bath at $-50^{\circ} \mathrm{C}$. The flask was heated up to $170^{\circ} \mathrm{C}$ in approximately 1 hour. The 2-butynenitrile sample produced during this process was vaporized as it was formed and selectively condensed in the second trap. Thanks to these trapping temperatures, 2-butynenitrile was obtained in a $77 \%$ yield $(3.0 \mathrm{~g}, 46 \mathrm{mmol})$ with a very high purity $(\sim 99 \%)$ checked by NMR spectroscopy.

The experiments were carried out on the DESIRS VacuumUltraViolet (VUV) beamline at the SOLEIL synchrotron facility in St. Aubin (France)[29] operating in the 8-bunch mode. This beamline is equipped with a $6.65 \mathrm{~m}$ normal incidence monochromator and a gas filter to eliminate the higher harmonics of the undulator [30]. The VUV photon flux was monitored independently by a calibrated gold grid VUV detector in order to normalize the spectrum intensities.

The experimental setup CERISES used in this work was installed on the DESIRS beam line and has already been described previously [31]. Here we limit the description to the specific details of our experiment. Briefly, the $\mathrm{CH}_{3} \mathrm{C}_{3} \mathrm{~N}$ gaseous molecules were introduced in a very low-pressure chamber $\left(\approx 2 \times 10^{-6} \mathrm{mbar}\right)$ at room temperature where they were excited by the VUV synchrotron radiation. Ions produced by the direct or dissociative ionization processes were mass-selected and guided towards the micro channel plate detector using a first quadrupolar mass filter, two octopolar guides and a second quadrupolar mass filter. The photoelectrons with near zero-kinetic energy (so-called threshold photoelectrons) were collected in the opposite direction and selected by geometrical and temporal discrimination criteria. The photon resolution of the TPES was approximately $4 \mathrm{meV}$ below $15.5 \mathrm{eV}$ and $10 \mathrm{meV}$ above $15.5 \mathrm{eV}$. The corresponding overall resolution of the spectra, including the resolution of the photons and of the photoelectrons, was measured at $10 \mathrm{meV}$ (around $80 \mathrm{~cm}^{-1}$ ) below $15.5 \mathrm{eV}$ and about $15 \mathrm{meV}$ above $15.5 \mathrm{eV}$ in the present experimental conditions. For the dissociative ionization study, the fragment ion yields were recorded at lower resolution $(15 \mathrm{meV})$. The photon energy scale of all spectra was calibrated with an accuracy of $1 \mathrm{meV}\left(8 \mathrm{~cm}^{-1}\right)$ using the argon and neon absorption lines observed in the ion signals due to their presence in the beamline gas filter. Note that these rare gas absorptions were not fully corrected by the normalisation procedure since the photon flux was recorded with a different spectral resolution.

\section{Theoretical calculations}

All electronic structure calculations were carried out using the Gaussian09 suite of programs [32]. Equilibrium geometries and vibrational harmonic frequencies were computed for the neutral and cation electronic ground states using DFT with the hybrid functional B97-1 [33], in combination with the basis set aug-cc-pvtz (AVTZ) and a grid of size $(99,590)$.

\subsection{Equilibrium geometries and vibrational frequencies for the electronic ground states}

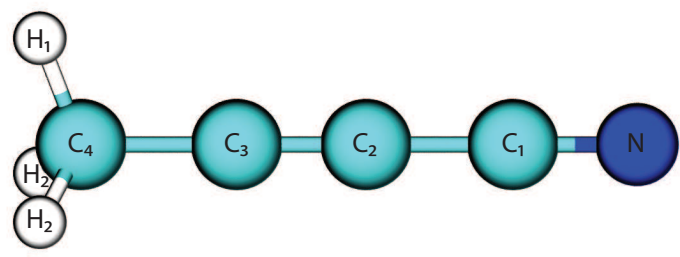

Figure 1: $\mathrm{CH}_{3} \mathrm{C}_{3} \mathrm{~N}$ molecule structure. The labels correspond to the ones used in Table 1.

The symmetry of the equilibrium geometry of the neutral ground state of $\mathrm{CH}_{3} \mathrm{C}_{3} \mathrm{~N}$ was found to belong to the $\mathrm{C}_{3 \mathrm{v}}$ point group. The optimised equilibrium geometry of the cation 
ground state was found to be of $\mathrm{C}_{\mathrm{s}}$ symmetry due to distorsion resulting from a Jahn-Teller interaction. Note that a similar situation is encountered in the propyne cation ground state $\left(\mathrm{CH}_{3} \mathrm{C}_{2} \mathrm{H}^{+}\right)$[34]. The calculated equilibrium geometries of neutral and cationic $\mathrm{CH}_{3} \mathrm{C}_{3} \mathrm{~N}$ are detailed in Table 1 with the labels defined in Fig. 1 corresponding to the molecular geometry in the $\mathrm{C}_{\mathrm{s}}$ symmetry group. They are compared with earlier experimental [16] and theoretical [26] values obtained for the neutral species. The present calculated structure for neutral $\mathrm{CH}_{3} \mathrm{C}_{3} \mathrm{~N}$ is in very good agreement with the geometrical structure determined by microwave rotational spectroscopy [16].

Table 1: Calculated and experimental bond distances $(\AA)$ and angles (degrees) for $\mathrm{CH}_{3} \mathrm{C}_{3} \mathrm{~N}$ in neutral and cationic electronic ground states. The values from this work are in bold font.

\begin{tabular}{ccccc} 
& \multicolumn{3}{c}{$\mathrm{CH}_{3} \mathrm{C}_{3} \mathrm{~N}\left(\mathrm{C}_{3 \mathrm{v}}\right)$} & $\mathrm{CH}_{3} \mathrm{C}_{3} \mathrm{~N}^{+}\left(\mathrm{C}_{\mathrm{s}}\right)$ \\
\cline { 2 - 4 } calc. $^{b}$
\end{tabular}

${ }^{a} \mathrm{HF} / 4-21 \mathrm{G}^{*}$, calculated values from Ref. [26]

${ }^{b}$ B971/AVTZ, this work

${ }^{c}$ Experimental values from Ref. [16]

In Table 2, the calculated vibrational frequencies of $\mathrm{CH}_{3} \mathrm{C}_{3} \mathrm{~N}$ and $\mathrm{CH}_{3} \mathrm{C}_{3} \mathrm{~N}^{+}$in their electronic ground states are reported. Their respective geometries belonging to different point groups $\left(\mathrm{C}_{3 \mathrm{v}}\right.$ and $\left.\mathrm{C}_{\mathrm{s}}\right)$ imply different labels for the vibrational normal modes. The normal modes in the cation are strongly modified with respect to the neutral normal modes. These modes are related to the eigenstates $\chi_{i, p}$ of the force constant matrix $D_{i j}=h_{i j} / \sqrt{m_{i} m_{j}}$ where $h_{i j}=\partial^{2} V / \partial r_{i} \partial r_{j}$ is the second derivative of the potential forming the Hessian matrix and $m_{i}$ the mass of atom $i$. Each of the two charge states, neutral and cation, gives rise to one set of eigenstates $\chi_{i, d, p}$ and $\chi_{i, p}^{\prime}$, respectively, where the index $d$ for the neutral molecule is an index over the degeneracy of vibrational mode $p$ corresponding to the $\mathrm{C}_{3 \mathrm{v}}$ symmetry group. To quantify how much the normal modes in the cation are modified with respect to the neutral molecule, we introduce the Squared Dushinsky (SD) matrix defined as

$$
\left|\Delta_{p, q}\right|^{2}=\sum_{d}\left|\sum_{i} \chi_{i, d, p} \chi_{i, q}^{\prime}\right|^{2}
$$

In Fig. 2, a map plot of the SD matrix is shown as a function of the neutral and cation mode number. Among the symmetric normal modes of the neutral species (of $\mathrm{a}_{1}$ symmetry), one can see that the $v_{2}, v_{3}, v_{5}$ and $v_{6}$ normal modes correlate almost exclusively to the $v_{3}^{+}, v_{4}^{+}, v_{7}^{+}$and $v_{9}^{+}$normal modes of the cation, respectively. For the degenerate e mode of the neutral species, only the $v_{10}$ and $v_{12}$ modes can be associated in good approximation with the couples of mode $\left(v_{10}^{+}, v_{15}^{+}\right)$and $\left(v_{12}^{+}, v_{18}^{+}\right)$ of the cation, respectively. Note that the calculated vibrational frequencies corresponding to these couples are degenerate or quite close (see Table 2). The other normal modes of the neutral molecule $\left(v_{1}, v_{4}, v_{7}, v_{8}, v_{9}\right.$ and $\left.v_{11}\right)$ are more delocalised over the normal modes of the cation. Thus, one cannot easily compare these latter vibrational modes between the neutral and the cation without crude approximations. The correlations between the normal modes of the neutral species and the cation are summarized in Table A.10 of Appendix A.

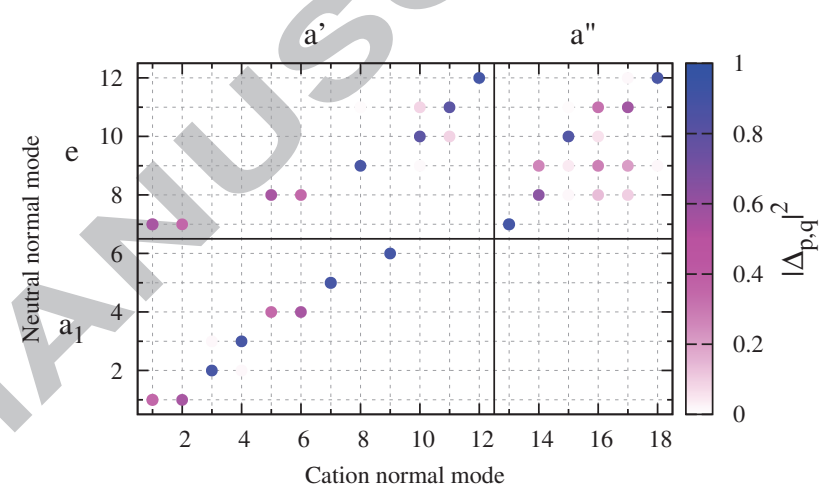

Figure 2: Map plot of the Squared Dushinsky matrix of $\mathrm{CH}_{3} \mathrm{C}_{3} \mathrm{~N}$ (see text for more details). The color scale indicates the correlation degree between the neutral and cation normal modes in the ground states.

From the harmonic frequencies and normal modes in the neutral and cation ground states, the Franck-Condon (FC) factors have been calculated for the $\tilde{\mathrm{X}}^{+2} \mathrm{E} \leftarrow \tilde{\mathrm{X}}{ }^{1} \mathrm{~A}_{1}$ transition using the harmonic approximation for the potential energy surfaces and the Condon approximation for the dipole moment. The FC integrals were computed, including the Duschinsky effect, using recursive formulæ already implemented in Gaussian09 [35]. The strongest Franck-Condon factors are reported in Table B.11 of Appendix B. From the Franck-Condon factors, the TPES at $0 \mathrm{~K}$ was computed by convoluting the stick spectrum with a Gaussian line shape of $160 \mathrm{~cm}^{-1}$ full-width at half maximum (FWHM), which reproduces well the observed band widths resulting from the spectral resolution and the rotational band profile.

\subsection{Dissociative ionization thresholds}

$\mathrm{CH}_{3} \mathrm{C}_{3} \mathrm{~N}$ ionization energy and product dissociative ionization thresholds were calculated and corrected for zero-point energies (ZPE). The thresholds were calculated only for the channels leading to the lower electronic states of the fragments $\left(\mathrm{S}_{0}\right.$ singlet or $\mathrm{T}_{1}$ triplet states for fragments with odd spin multiplicity, and $\mathrm{D}_{0}$ doublet states for even spin multiplicity). Note that the present calculations have been carried out at $0 \mathrm{~K}$ and thus do not take into account the temperature dependence of the threshold. The observed appearance energies might also be 
Table 2: Calculated harmonic frequencies for $\mathrm{CH}_{3} \mathrm{C}_{3} \mathrm{~N}$ in neutral and cationic electronic ground states in the $\mathrm{C}_{3 \mathrm{v}}$ and $\mathrm{C}_{\mathrm{s}}$ point group, respectively. The symmetry of the modes and their approximate description are also reported. All values are in $\mathrm{cm}^{-1}$.

\begin{tabular}{|c|c|c|c|c|c|c|}
\hline \multirow[b]{2}{*}{ mode } & \multicolumn{3}{|l|}{$\mathrm{CH}_{3} \mathrm{C}_{3} \mathrm{~N}\left(\mathrm{C}_{3 \mathrm{v}}\right)$} & \multicolumn{3}{|l|}{$\mathrm{CH}_{3} \mathrm{C}_{3} \mathrm{~N}^{+}\left(\mathrm{C}_{\mathrm{s}}\right)$} \\
\hline & description & symmetry & $\tilde{v}$ & description & symmetry & $\tilde{v}^{+}$ \\
\hline 1 & $\mathrm{CH}_{3}$ sym. stretch & $a_{1}$ & 3023 & $\mathrm{CH}_{3}$ stretch & $\mathrm{a}^{\prime}$ & 3016 \\
\hline 2 & $\mathrm{C} \equiv \mathrm{N}, \mathrm{C} \equiv \mathrm{C}$ stretches (in phase) & $a_{1}$ & 2384 & $\mathrm{CH}_{3}$ stretch & & 2901 \\
\hline 3 & $\mathrm{C} \equiv \mathrm{N}, \mathrm{C} \equiv \mathrm{C}$ stretches (opposite phase) & $a_{1}$ & 2252 & $\mathrm{C} \equiv \mathrm{N}, \mathrm{C} \equiv \mathrm{C}$ stretches (in phase) & & 2275 \\
\hline 4 & $\mathrm{CH}_{3}$ sym. deformation & $a_{1}$ & 1403 & $\mathrm{C} \equiv \mathrm{N}, \mathrm{C} \equiv \mathrm{C}$ stretches (opposite phase) & $\mathrm{a}^{\prime}$ & 2018 \\
\hline 5 & C-C stretches (opposite phase) & $a_{1}$ & 1174 & $\mathrm{CH}_{3}$ deformation & $a^{\prime}$ & 1413 \\
\hline 6 & C-C stretches (in phase) & $a_{1}$ & 670 & $\mathrm{CH}_{3}$ deformation & $a^{\prime}$ & 1305 \\
\hline 7 & $\mathrm{CH}_{3}$ asym. stretch & $\mathrm{e}$ & 3090 & C-C stretches (opposite phase) & $a^{\prime}$ & 1224 \\
\hline 8 & $\mathrm{CH}_{3}$ asym. deformation & $\mathrm{e}$ & 1464 & $\mathrm{CH}_{3}$ rock & $\mathrm{a}^{\prime}$ & 913 \\
\hline 9 & $\mathrm{CH}_{3}$ rock & $\mathrm{e}$ & 1042 & C-C stretches (in phase) & $\mathrm{a}^{\prime}$ & 680 \\
\hline 10 & $\mathrm{C}-\mathrm{C} \equiv \mathrm{C}-\mathrm{C} \equiv \mathrm{N}$ skeleton bend & $\mathrm{e}$ & 537 & $\mathrm{C}-\mathrm{C} \equiv \mathrm{C}-\mathrm{C} \equiv \mathrm{N}$ skeleton bend & $\mathrm{a}^{\prime}$ & 499 \\
\hline 11 & $\mathrm{C}-\mathrm{C} \equiv \mathrm{C}-\mathrm{C} \equiv \mathrm{N}$ skeleton bend & $\mathrm{e}$ & 357 & $\mathrm{C}-\mathrm{C} \equiv \mathrm{C}-\mathrm{C} \equiv \mathrm{N}$ skeleton bend & $a^{\prime}$ & 346 \\
\hline 12 & $\mathrm{C}-\mathrm{C} \equiv \mathrm{C}-\mathrm{C} \equiv \mathrm{N}$ skeleton bend & $\mathrm{e}$ & 146 & $\mathrm{C}-\mathrm{C} \equiv \mathrm{C}-\mathrm{C} \equiv \mathrm{N}$ skeleton bend & $a^{\prime}$ & 133 \\
\hline 13 & & & & $\mathrm{CH}_{3}$ stretch & $a^{\prime \prime}$ & 3021 \\
\hline 14 & & & & $\mathrm{CH}_{3}$ deformation & $a^{\prime \prime}$ & 1233 \\
\hline 15 & & & & $\mathrm{C}-\mathrm{C} \equiv \mathrm{C}-\mathrm{C} \equiv \mathrm{N}$ skeleton bend $+\mathrm{CH}_{3}$ def. & $a^{\prime \prime}$ & 507 \\
\hline 16 & & & & $\mathrm{C}-\mathrm{C} \equiv \mathrm{C}-\mathrm{C} \equiv \mathrm{N}$ skeleton bend $+\mathrm{CH}_{3}$ def. & $a^{\prime \prime}$ & 440 \\
\hline 17 & & & & $\mathrm{C}-\mathrm{C} \equiv \mathrm{C}-\mathrm{C} \equiv \mathrm{N}$ skeleton bend $+\mathrm{CH}_{3}$ def. & $a^{\prime \prime}$ & 239 \\
\hline 18 & & & & $\mathrm{C}-\mathrm{C} \equiv \mathrm{C}-\mathrm{C} \equiv \mathrm{N}$ skeleton bend & $a^{\prime \prime}$ & 133 \\
\hline
\end{tabular}

affected by possible activation barriers which are not included in the calculations. Nevertheless, these crude approximations allowed us to identify the observed dissociative channels (see section 4.2).

\section{Results and discussion}

\subsection{Photoionization of cyanopropyne}

The $\mathrm{CH}_{3} \mathrm{C}_{3} \mathrm{~N}^{+}$ion yield and the threshold photoelectron spectrum of $\mathrm{CH}_{3} \mathrm{C}_{3} \mathrm{~N}$ have been recorded in the [86000$180000 \mathrm{~cm}^{-1}$ ] region for the first time and are displayed in Fig.3.

The TPES spectrum is quite similar to the PES spectrum reported by Bieri et al. [21], leading to observation of six electronic states. The assignments of the different electronic states have been determined in Ref.[21] and are reported in Fig.3. The ionization thresholds measured in the present work towards the different electronic states of the cation are summarized in Table 3 and compared with previous studies. The three lowest electronic states, $\tilde{\mathrm{X}}^{+2} \mathrm{E}, \tilde{\mathrm{A}}^{+2} \mathrm{~A}_{1}$ and $\tilde{\mathrm{B}}^{+2} \mathrm{E}$, exhibit a sharp peak at their origin followed by vibrational progressions. Their origins are located at $86872 \pm 20 \mathrm{~cm}^{-1}, 105354 \pm 20 \mathrm{~cm}^{-1}$ and $107848 \pm 20 \mathrm{~cm}^{-1}$, respectively (see Table 3 ), in good agreement with Bieri et al. values within their error bars [21]. The disagreement with the results of Asbrink et al. is suspected to come from their calibration procedure in which they only used one argon line for the calibration of the entire range of the spectrum (from 9 to $27 \mathrm{eV}$ ) [22]. The three next states $\tilde{\mathrm{C}}^{+}$, $\tilde{\mathrm{D}}^{+}$and $\tilde{\mathrm{E}}^{+}$are much broader and unresolved, except for the $\tilde{\mathrm{C}}^{+}$ state. This indicates a predissociative character for the $\tilde{\mathrm{D}}^{+}$and $\tilde{\mathrm{E}}^{+}$states and important alterations in the geometry of the $\tilde{\mathrm{C}}^{+}$ state with respect to the ground state of the neutral species.
Table 3: Ionization thresholds towards the different electronic states of $\mathrm{CH}_{3} \mathrm{C}_{3} \mathrm{~N}^{+}$. All values are in $\mathrm{cm}^{-1}$ and correspond to adiabatic energies unless specified. Experimental error bars are given in parenthesis.

\begin{tabular}{c|ccc} 
& This work & Bieri et al. [21] & Asbrink et al. [22] \\
$\tilde{\mathrm{X}}^{+2} \mathrm{E}$ & $86872(20)$ & $86947(160)$ & $88318(160)$ \\
$\tilde{\mathrm{A}}^{+2} \mathrm{~A}_{1}$ & $105354(20)$ & $105336(160)$ & $105336(160)$ \\
$\tilde{\mathrm{B}}^{+2} \mathrm{E}$ & $107848(20)$ & $107836(160)$ & $109046(160)$ \\
$\tilde{\mathrm{C}}^{+}$ & $119390(50)$ & $121790(800)^{b}$ & $122596(800)^{b}$ \\
$\tilde{\mathrm{D}}^{+}$ & $130160(500)^{a, b}$ & $131468(800)^{b}$ & $133081(800)^{b}$ \\
$\tilde{\mathrm{E}}^{+}$ & $164300(500)^{b}$ & $165344(800)^{b}$ & $165344(800)^{b}$ \\
\hline
\end{tabular}

${ }^{a}$ Tentative value (see text).

${ }^{b}$ Value for the vertical ionization threshold derived from the position of the band maximum.

It is of interest to mention that the measured ionization thresholds towards the $\tilde{\mathrm{X}}^{+}$and $\tilde{\mathrm{B}}^{+}$states of cyanopropyne cation (10.77 eV and $13.37 \mathrm{eV}$, respectively) are very close to the first ionization threshold of propyne (10.37 eV [36]) and hydrogen cyanide (13.6 eV [37]), respectively. This situation is similar to what was encountered in the case of cyanoacetylene [38] for which the ionization thresholds were close to the one of acetylene and hydrogen cyanide. This trend was explained for cyanoacetylene by the removal of a $\pi$ electron more localised on the $\mathrm{C} \equiv \mathrm{C}$ bond for the $\mathrm{X}^{+}$state or on the $\mathrm{C} \equiv \mathrm{N}$ bond for the $\mathrm{B}^{+}$state. By analogy, we propose that the removal of an electron from the (3e) molecular orbital leading to the $\tilde{X}^{+2} \mathrm{E}$ state of cyanopropyne cation is more localised on the $\mathrm{C} \equiv \mathrm{C}$ bond. Similarly, the $\tilde{\mathrm{B}}^{+2} \mathrm{E}$ state is formed by the ejection of an electron from the (2e) molecular orbital more localised on the $\mathrm{C} \equiv \mathrm{N}$ bond. 


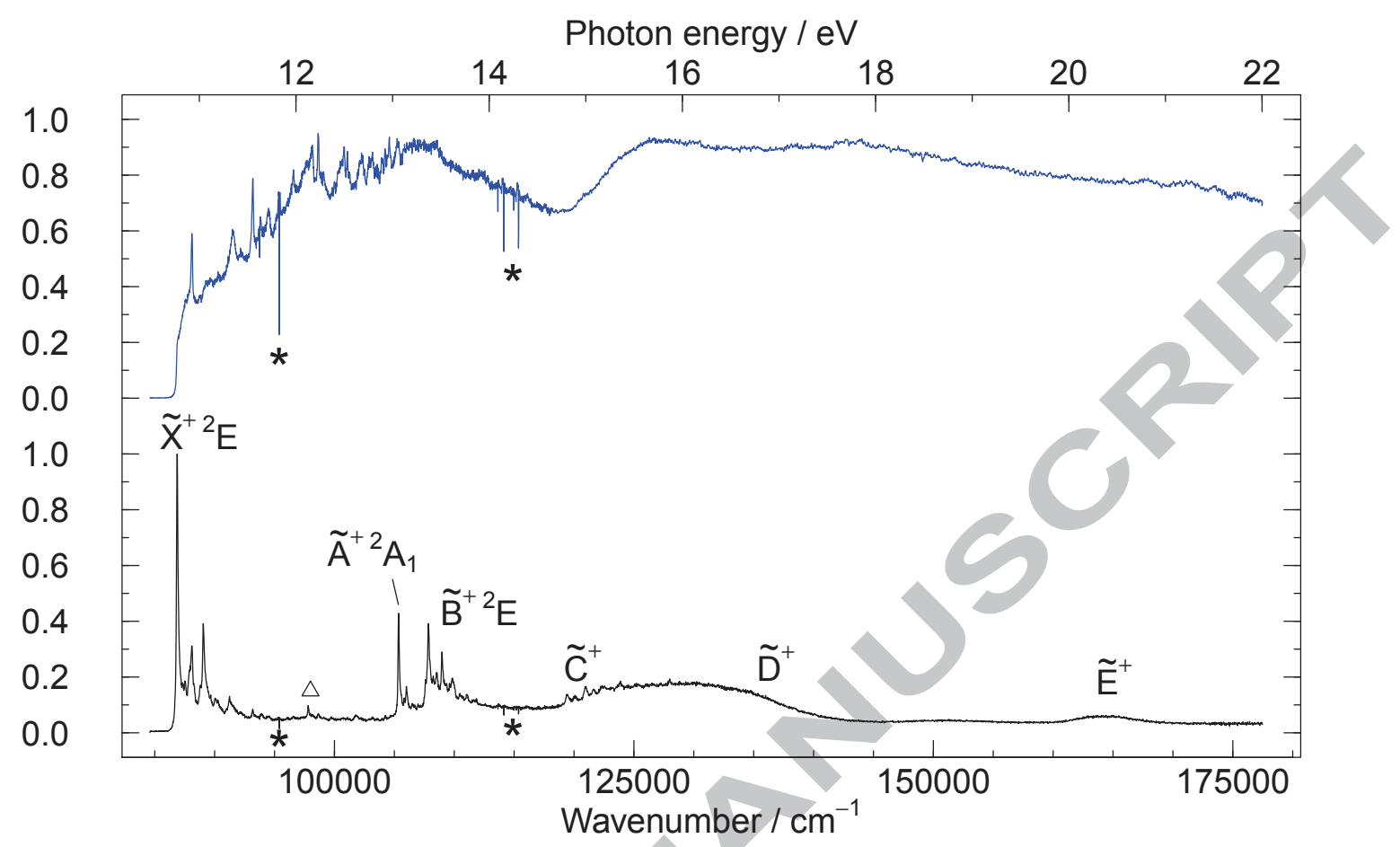

Figure 3: $\mathrm{CH}_{3} \mathrm{C}_{3} \mathrm{~N}^{+}$ion yield (in blue) and overview of $\mathrm{CH}_{3} \mathrm{C}_{3} \mathrm{~N}$ threshold photoelectron (in black) spectra between 10 and $22 \mathrm{eV}$. The triangle corresponds to electron signal due to ionization of an impurity and asterisks to argon absorption lines (see text).

Above the first ionization threshold $\left(86872 \mathrm{~cm}^{-1}\right)$, the ion yield shown in Fig. 3 exhibits sharp structures up to $105000 \mathrm{~cm}^{-1}$ which correspond to autoionization of Rydberg series converging to the $\tilde{\mathrm{A}}^{+}$and $\tilde{\mathrm{B}}^{+}$excited electronic states of the cation. The assignments of these series will be discussed in a forthcoming paper. Above $109300 \mathrm{~cm}^{-1}$, the ion yield significantly decreases up to $120000 \mathrm{~cm}^{-1}$. This range corresponds to the gap between the $\tilde{\mathrm{B}}^{+}$and $\tilde{\mathrm{C}}^{+}$electronic states and no Rydberg series converging to the $\tilde{\mathrm{C}}^{+}$electronic state is observed. Therefore we attribute this drop in the $\mathrm{CH}_{3} \mathrm{C}_{3} \mathrm{~N}^{+}$ion yield to the opening of different dissociative ionization channels (see section 4.2). The ion signal increases again around $120000 \mathrm{~cm}^{-1}$ corresponding to the opening of the $\tilde{\mathrm{C}}^{+}$ionization channel.

An important remark concerns the mode labelling adopted throughout this paper. Indeed, the vibrational modes are different between the neutral and cation electronic ground state in their respective point group, as discussed in section 3, and the same situation is probably encountered in the other electronic states. In earlier works, the $\mathrm{C}_{3 \mathrm{v}}$ notations were used. Here, all electronic structure calculations are limited to the $\tilde{\mathrm{X}}^{+}$electronic ground state. Consequently, the proposed assignment for the vibronic transitions to the $\tilde{\mathrm{X}}^{+}$electronic ground state is derived from our calculations of the vibronic structure of $\tilde{X}^{+}$state in the $\mathrm{C}_{\mathrm{s}}$ symmetry but the labels are converted into the $\mathrm{C}_{3 \mathrm{v}}$ notation (see Fig. 2 and Table A.10 of Appendix A). The proposed assignment for the vibronic transitions to the $\widetilde{\mathrm{A}}^{+}, \tilde{\mathrm{B}}^{+}$and $\widetilde{\mathrm{C}}^{+}$states are derived only by comparison with the vibrational structure of the neutral electronic ground state.

Hence, we choose in this paper to use the vibrational mode labels of the neutral species in the $\mathrm{C}_{3 \mathrm{v}}$ point group for the transitions to the cation vibronic states. For example, Fig. 4 a) shows the TPES spectrum of the $\tilde{X}^{+}{ }^{2} \mathrm{E} \leftarrow \tilde{\mathrm{X}}{ }^{1} \mathrm{~A}_{1}$ transition, which exhibits a progression in the symmetric $\mathrm{C} \equiv \mathrm{N}$ and $\mathrm{C} \equiv \mathrm{C}$ stretches. Using the $\mathrm{C}_{3 \mathrm{v}}$ labels (neutral symmetry), this corresponds to the $v_{2}$ mode, but in the $\mathrm{C}_{\mathrm{s}}$ symmetry of the ion, this mode would correspond to the $v_{3}^{+}$mode (as defined in Table 2). The assignments of the vibronic transitions to the four lowest electronic states of the cation are presented below.

\subsubsection{The $\tilde{\mathrm{X}}^{+2} \mathrm{E} \leftarrow \tilde{\mathrm{X}}{ }^{1} \mathrm{~A}_{1}$ transition}

Figs. 4 a) and 4 b) display the experimental TPES spectrum (in black) in the vicinity of the $\tilde{\mathrm{X}}^{+}$electronic ground state of $\mathrm{CH}_{3} \mathrm{C}_{3} \mathrm{~N}^{+}$and the corresponding calculated spectrum (in red). Only an horizontal shift has been applied to the calculated spectrum to match the $0^{0}$ band position of the experimental spectrum. Although DFT being monoconfigurational is not fully appropriate to describe the $\mathrm{CH}_{3} \mathrm{C}_{3} \mathrm{~N}^{+}$electronic ground state which is affected by Jahn-Teller effect, the overall agreement between the calculated and experimental spectra is quite good. The main discrepancies are the positions of the $9^{1}$ and $2^{1}$ bands (and therefore the combination bands involving these modes) which can be explained by anharmonic effect, and the band intensities in the $87750-89000 \mathrm{~cm}^{-1}$ range (see Fig. $4 \mathrm{~b}$ )) which will be discussed later in this section. 


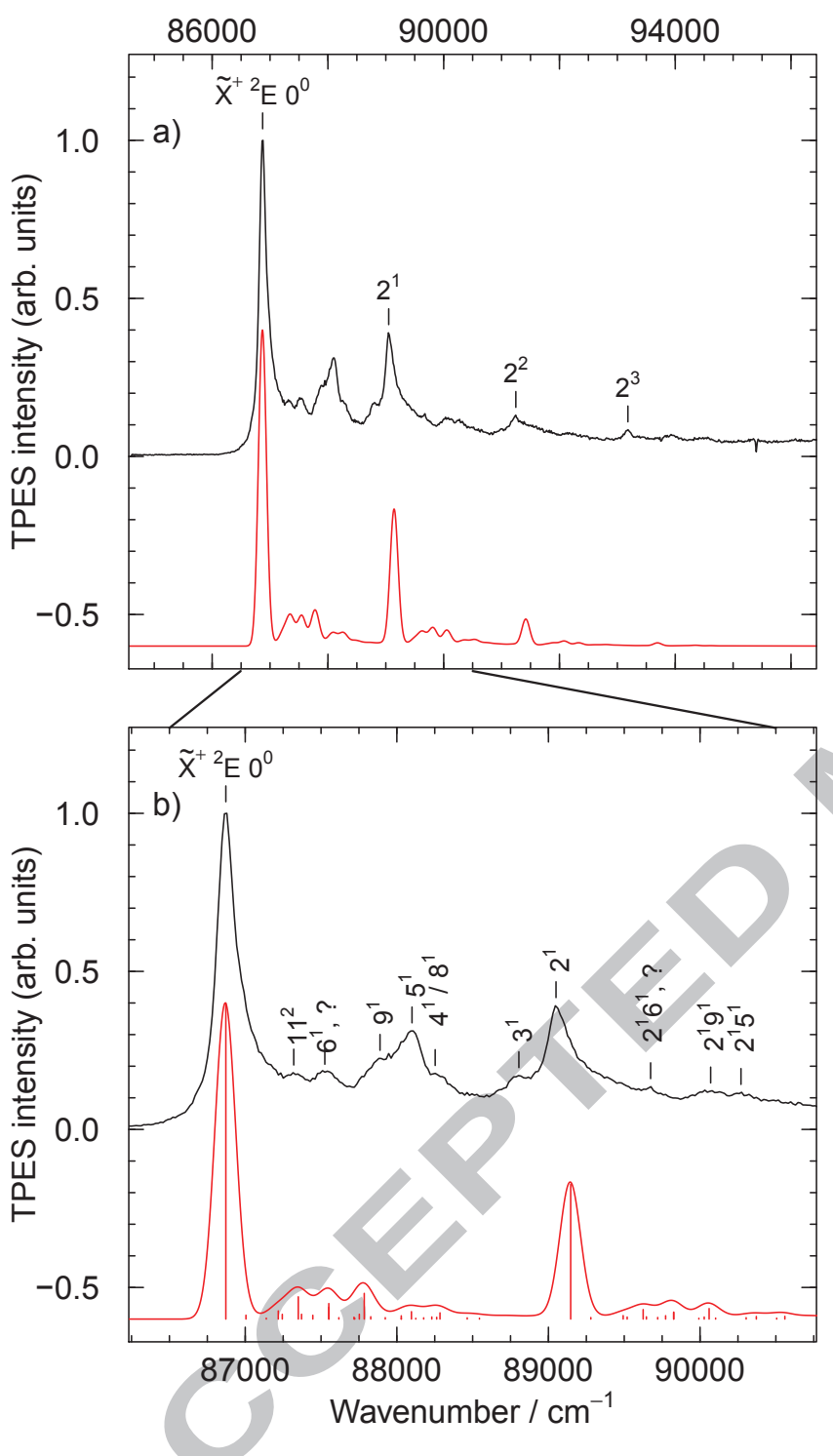

Figure 4: Panel a) Experimental threshold photoelectron spectrum of $\mathrm{CH}_{3} \mathrm{C}_{3} \mathrm{~N}$ in the vicinity of the $\tilde{\mathrm{X}}^{+}{ }^{2} \mathrm{E} \leftarrow \tilde{\mathrm{X}}{ }^{1} \mathrm{~A}_{1}$ transition (in black) with the calculated TPES spectrum (in red). The calculated stick spectrum has been convoluted with a gaussian line shape $\left(\mathrm{FWHM}=160 \mathrm{~cm}^{-1}\right.$ ) for clarity. Panel b) Zoom of the same spectra between 86250 and $90750 \mathrm{~cm}^{-1}$. The assignments of the $\tilde{X}^{+}$ vibrational states are given with the neutral normal mode notations. For clarity, the calculated spectrum is shifted down. The question mark accounts for normal modes of the cation which have no equivalent in the $\mathrm{C}_{3 \mathrm{v}}$ point group (see text for details).
In the Born-Oppenheimer approximation, a transition between the neutral vibronic ground state and a vibronic state of the cation is allowed only if the product of the vibrational wavefunctions contains a symmetric component. Therefore, in $\mathrm{C}_{3 \mathrm{v}}$ symmetry, the modes of e symmetry should be reached only with even quanta of excitation whereas the modes of $a_{1}$ symmetry should be reached with even and odd quanta of excitation. In the present case, the e modes correlate with $\mathrm{a}^{\prime}+\mathrm{a}^{\prime \prime}$ components in the $\mathrm{C}_{\mathrm{s}}$ point group. Consequently, the transition to odd quanta of excitation is allowed for the e modes through the $\mathrm{a}^{\prime}$ components.

In Fig. 4 a), one can see the main vibrational progression due to the $v_{2}$ mode $(\mathrm{C} \equiv \mathrm{N}$ and $\mathrm{C} \equiv \mathrm{C}$ stretches in phase, with $\mathrm{a}_{1}$ symmetry) due to the changes of the $\mathrm{C} \equiv \mathrm{N}$ and $\mathrm{C} \equiv \mathrm{C}$ bond lengths upon ionization (see Table 1). The corresponding vibrational wavenumber is decreased (from $2271 \mathrm{~cm}^{-1}$ in the neutral species to $2178 \pm 20 \mathrm{~cm}^{-1}$ in the cation) which is consistent with the predicted increases of these bond lengths. The calculated TPES spectrum confirms the observed progression in the $v_{2}$ mode (with the neutral notation in the $\mathrm{C}_{3 \mathrm{v}}$ point group) but the calculated vibrational wavenumber and intensity of the $2^{n}$ bands are slightly overestimated. Close to the $2^{1}$ band, one can see (Fig. 4 b)) that the $3^{1}$ band (which corresponds to the $\mathrm{C} \equiv \mathrm{N}$ and $\mathrm{C} \equiv \mathrm{C}$ stretches in opposite phase) is observed in the experimental spectrum unlike in the calculated spectrum. We suspect that the $v_{2}$ and $v_{3}$ normal modes or the $\mathrm{C} \equiv \mathrm{C}$ and $\mathrm{C} \equiv \mathrm{N}$ bond lengths are not well described with our calculations and that the calculated intensity of the $2^{1}$ band is actually spread over the $2^{1}$ and $3^{1}$ observed bands.

The intensity disagreement around the position of the $5^{1}$ band can also be attributed to the limited validity of our calculation. In addition, the TPES intensity in this region is likely affected by autoionization. Indeed, in the ion yield spectrum displayed in Fig. 3, one can see a very strong line located at the same energy $\left(88100 \mathrm{~cm}^{-1}\right)$ which is the signature of an efficient autoionization process.

The other bands are quite well reproduced but their labels are not trivial. As mentioned above, we use the $\mathrm{C}_{3 \mathrm{v}}$ notation for the vibrational mode labelling but the calculation results are given with the $\mathrm{C}_{\mathrm{s}}$ notation labels. The calculated band that we label $11^{2}$ is actually the $17^{2}$ band in $\mathrm{C}_{\mathrm{s}}$ notation (see Table A.10 in Appendix A). In Fig. 2, the SD matrix shows that the projection of the $v_{17}^{+}$cation normal mode over the normal modes of the neutral species is actually spread over the $v_{11}$ mode (with the higher contribution) and the $v_{9}$ and $v_{8}$ modes. For the same reason, the band which overlaps in the calculated spectrum with the band that we label $6^{1}$ ( $9^{1}$ in the $C_{\mathrm{s}}$ notation) is the $16^{1} 17^{1}$ band. From the map plot of the SD matrix, we cannot derive a corresponding mode in the $\mathrm{C}_{3 \mathrm{v}}$ notation. That is why we use the question mark in Fig. 4 b). The last ambiguous band is the one labeled $4^{1} / 8^{1}$. Indeed the calculated spectrum gives a transition at this energy with corresponds to the $5^{1}$ transition in the $\mathrm{C}_{\mathrm{s}}$ notation. Again, from the SD matrix, this normal mode of the cation is associated to the $v_{4}$ and $v_{8}$ normal modes of the neutral species.

The position of the bands with their labels in the $\mathrm{C}_{3 \mathrm{v}}$ notation are listed in Table 4. The corresponding vibrational wavenum- 
bers are compared with the earlier work of Bieri et al. [21] in Table 8. We find that the values for the $v_{2}$ and $v_{9}$ vibrational modes obtained by Bieri et al. are in good agreement with the present results within the error bars.

Table 4: Band wavenumbers and assignments of the $\tilde{\mathrm{X}}^{+}{ }^{2} \mathrm{E} \leftarrow \tilde{\mathrm{X}}{ }^{1} \mathrm{~A}_{1}$ vibronic transitions observed in the TPES. All values are in $\mathrm{cm}^{-1}$.

\begin{tabular}{ccc} 
Wavenumber & Wavenumber $-I P\left(\tilde{\mathrm{X}}^{+}\right)^{a}$ & $\begin{array}{c}\text { Upper level } \\
\text { assignment }\end{array}$ \\
\hline 86872 & 0 & $0^{0}$ \\
87320 & 448 & $11^{2}$ \\
87525 & 653 & $6^{1}$ and $?$ \\
87889 & 1017 & $9^{1}$ \\
88100 & 1228 & $5^{1}$ \\
88253 & 1381 & $4^{1} / 8^{1}$ \\
88805 & 1933 & $3^{1}$ \\
89050 & 2178 & $2^{1}$ \\
89674 & 2802 & $2^{1} 6^{1}$ and $2^{1} ?$ \\
90070 & 3198 & $2^{1} 9^{1}$ \\
90270 & 3398 & $2^{1} 5^{1}$ \\
91246 & 4374 & $2^{2}$ \\
93182 & 6310 & $2^{3}$ \\
\hline
\end{tabular}

${ }^{a} \operatorname{IP}\left(\tilde{\mathrm{X}}^{+}\right)=86872 \mathrm{~cm}^{-1}$

\subsubsection{The $\tilde{\mathrm{A}}^{+2} \mathrm{~A}_{1} \leftarrow \tilde{\mathrm{X}}{ }^{1} \mathrm{~A}_{1}$ transition}

The region of the TPES spectrum which includes the vibronic transitions to the $\tilde{\mathrm{A}}^{+}$state is displayed in Fig. 5. Similarly to the transition to the $\tilde{\mathrm{X}}^{+}$state, the $v_{2}$ mode is active upon ionization and the transition towards $v_{2}=2$ vibrational state is probably hidden in the region of the transitions to the $\tilde{\mathrm{B}}^{+}$ states. The proximity of these two electronic states might lead to vibronic interactions. The other observed bands are assigned to transitions involving the $5^{1}, 6^{1}, 8^{1}, 9^{1}$ and $11^{2}$ transitions. The vibrational structure of this electronic transition being quite similar to the one inyolving the electronic ground state of the cation, we can suppose that the two lowest electronic states $\left(\tilde{\mathrm{X}}^{+}\right.$ and $\tilde{\mathrm{A}}^{+}$) have close equilibrium geometry. Higher-level calculations such as Complete Active Space Self-Consistent Field (CASSCF) would be necessary to confirm this hypothesis. The positions of the vibronic transitions presented in Fig. 5 are summarized in Table 5. The comparison of the derived vibrational wavenumbers with the work of Bieri et al. [21] and Fulara et al. [24] is reported in Table 8. Within the error bars, our value for the $v_{6}$ vibrational mode is consistent with the one obtained by Bieri et al.. The disagreement with the results of Fulara et al. probably comes from matrix effects. In addition, the authors mentioned that the fluorescence spectrum is strongly affected by non-radiative relaxation of the $\tilde{\mathrm{B}}^{+}$state towards the $\tilde{\mathrm{A}}^{+}$state.

\subsubsection{The $\tilde{\mathrm{B}}^{+2} \mathrm{E} \leftarrow \tilde{\mathrm{X}}{ }^{1} \mathrm{~A}_{1}$ transition}

The TPES spectrum in the vicinity of the $\tilde{\mathrm{B}}^{+2} \mathrm{E} \leftarrow \tilde{\mathrm{X}}^{1} \mathrm{~A}_{1}$ transition is also displayed in Fig. 5. Unlike for the transition to the $\tilde{\mathrm{X}}^{+}$and $\tilde{\mathrm{A}}^{+}$electronic states, the main vibrational progression is assigned to the $v_{5}$ mode ( $\equiv \mathrm{C}-\mathrm{C} \equiv$ stretch) with a vibra-
Table 5: Band wavenumbers and assignments of the $\tilde{\mathrm{A}}^{+2} \mathrm{~A}_{1} \leftarrow \tilde{\mathrm{X}}{ }^{1} \mathrm{~A}_{1}$ vibronic transitions observed in the TPES. All values are in $\mathrm{cm}^{-1}$.

\begin{tabular}{ccc} 
Wavenumber & Wavenumber $-I P\left(\tilde{\mathrm{A}}^{+}\right)^{a}$ & $\begin{array}{c}\text { Upper level } \\
\text { assignment }\end{array}$ \\
\hline 105354 & 0 & $0^{0}$ \\
105830 & 476 & $11^{2}$ \\
106009 & 655 & $6^{1}$ \\
106280 & 926 & $9^{1}$ \\
106513 & 1159 & $5^{1}$ \\
106688 & 1334 & $6^{2}$ \\
106975 & 1621 & $8^{1}$ \\
107600 & 2246 & $2^{1}$ \\
\hline${ }^{a} I P\left(\tilde{\mathrm{A}}^{+}\right)=105354 \mathrm{~cm}^{-1}$ & &
\end{tabular}

tional wavenumber of $1132 \pm 20 \mathrm{~cm}^{-1}$. The other transitions are mainly associated with the $v_{3}, v_{6}, v_{11}$ and $v_{12}$ vibrational modes and their combination bands with the $v_{5}$ mode.

On the right part of the spectrum, two broad features are observed around 110500 and $111700 \mathrm{~cm}^{-1}$. The assignments of these bands is not trivial. In this region, too many combination bands involving the $\tilde{\mathrm{A}}^{+}$and $\tilde{\mathrm{B}}^{+}$electronic states could be reasonably consistent with the overall vibronic structure of these two states. High-resolution spectra and more sophisticated calculations are necessary to unambiguously assign these bands and thus no attempt is made to do so. Table 6 summarizes the positions of the assigned bands of the $\tilde{\mathrm{B}}^{+}{ }^{2} \mathrm{E} \leftarrow \tilde{\mathrm{X}}{ }^{1} \mathrm{~A}_{1}$ transition. The derived vibrational wavenumbers are reported in Table 8. A good agreement is found with the $\tilde{v}_{5}$ and $\tilde{v}_{6}$ values measured by Bieri at al. [21] and Fulara et al. [24] within their error bars.

Table 6: Band wavenumbers and assignments of the $\tilde{\mathrm{B}}^{+}{ }^{2} \mathrm{E} \leftarrow \tilde{\mathrm{X}}{ }^{1} \mathrm{~A}_{1}$ vibronic transitions observed in the TPES. All values are in $\mathrm{cm}^{-1}$.

\begin{tabular}{ccc} 
Wavenumber & Wavenumber $-I P\left(\tilde{\mathrm{B}}^{+}\right)^{a}$ & $\begin{array}{c}\text { Upper level } \\
\text { assignment }\end{array}$ \\
\hline 107848 & 0 & $0^{0}$ \\
107970 & 122 & $12^{1}$ \\
108252 & 404 & $11^{2}$ \\
108541 & 693 & $6^{1}$ \\
108980 & 1132 & $5^{1}$ \\
109350 & 1502 & $5^{1} 10^{1}$ \\
109615 & 1767 & $5^{1} 6^{1}$ \\
109835 & 1987 & $3^{1}$ \\
110070 & 2222 & $5^{2}$ \\
111033 & 3185 & $5^{1} 3^{1}$ \\
111120 & 3272 & $5^{3}$ \\
\hline
\end{tabular}

${ }^{a} \operatorname{IP}\left(\tilde{\mathrm{B}}^{+}\right)=107848 \mathrm{~cm}^{-1}$

\subsubsection{The $\tilde{\mathrm{C}}^{+} \leftarrow \tilde{\mathrm{X}}{ }^{1} \mathrm{~A}_{1}$ and $\tilde{\mathrm{D}}^{+} \leftarrow \tilde{\mathrm{X}}{ }^{1} \mathrm{~A}_{1}$ transitions}

In Fig. 6, the TPES in the region of the $\tilde{\mathrm{C}}^{+}$and $\tilde{\mathrm{D}}^{+}$states is shown. In our spectrum, we are not able to unambiguously 


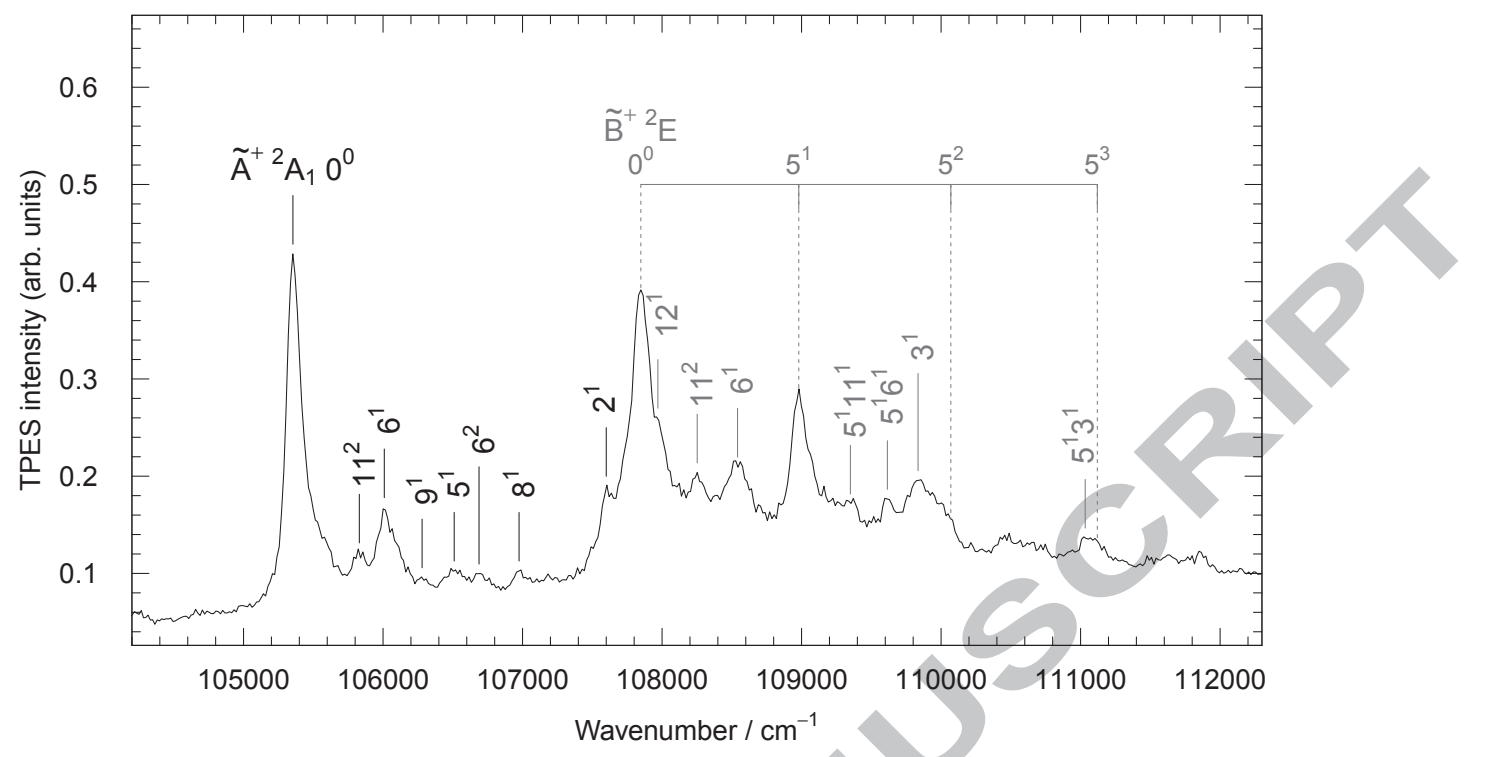

Figure 5: Threshold photoelectron spectrum of $\mathrm{CH}_{3} \mathrm{C}_{3} \mathrm{~N}$ in the vicinity of the $\tilde{\mathrm{A}}^{+2} \mathrm{~A}_{1} \leftarrow \tilde{\mathrm{X}}{ }^{1} \mathrm{~A}_{1}$ and $\tilde{\mathrm{B}}^{+}{ }^{2} \mathrm{E} \leftarrow \tilde{\mathrm{X}}{ }^{1} \mathrm{~A}_{1}$ transitions with the assignments of the $\tilde{\mathrm{A}}^{+}$ (in black) and $\tilde{\mathrm{B}}^{+}$(in gray) vibrational states.

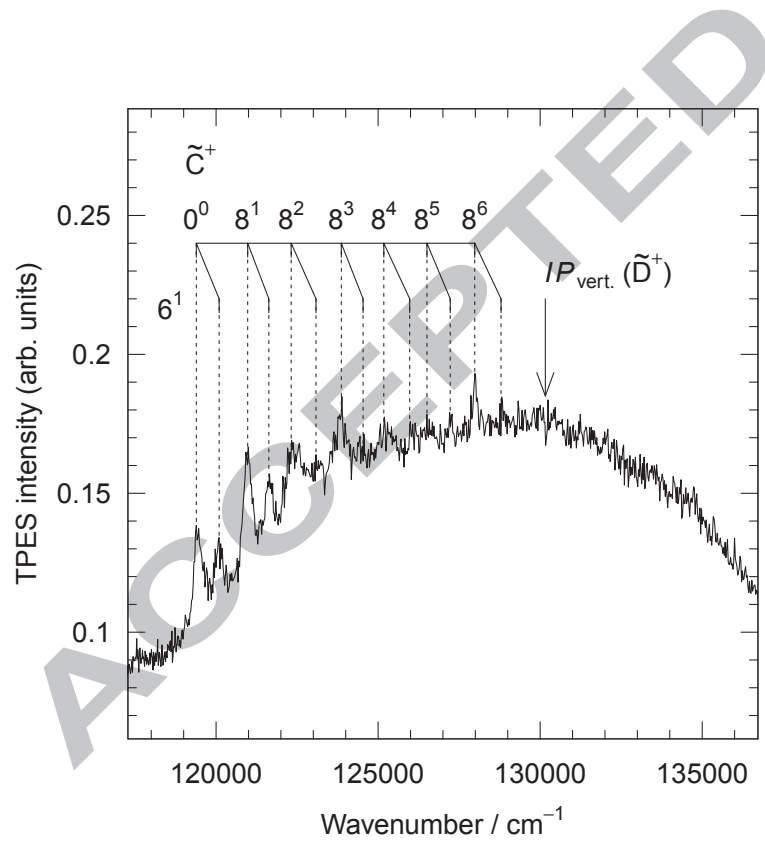

Figure 6: Threshold photoelectron spectrum of $\mathrm{CH}_{3} \mathrm{C}_{3} \mathrm{~N}$ in the vicinity of the $\tilde{\mathrm{C}}^{+} \leftarrow \tilde{\mathrm{X}}{ }^{1} \mathrm{~A}_{1}$ and $\tilde{\mathrm{D}}^{+} \leftarrow \tilde{\mathrm{X}}{ }^{1} \mathrm{~A}_{1}$ transitions with the assignments of the $\tilde{\mathrm{C}}^{+}$vibrational states. The tentative vertical ionization threshold of $\tilde{\mathrm{D}}^{+}$state is marked by an arrow. distinguish the $\tilde{\mathrm{C}}^{+}$and the $\tilde{\mathrm{D}}^{+}$states which strongly overlap as was observed already by Åsbrink et al. [22]. Surprisingly, these states seem more distinguishable in the spectrum of Bieri et al. although the resolution is less than ours [21]. Nevertheless, an extended vibrational progression is clearly observed on the red side of the broad band with a first intense peak at $119390 \pm 50 \mathrm{~cm}^{-1}$. We propose to assign this peak to the origin of the $\tilde{\mathrm{C}}^{+}$state regarding the sharp rise for this first peak with respect to the background signal and the evolution of the peak intensities over the band. If a vibronic transition with a smaller Franck-Condon factor existed at lower wavenumber, our signalto-noise ratio would allow us to observe it. It is clear in our spectrum that no such transition occurs. We assign the vibrational progression to the $v_{8}$ mode $\left(\mathrm{CH}_{3}\right.$ asymmetric deformation) with combination band with the $v_{6}$ mode (C-C stretches in phase) by comparing the corresponding vibrational wavenumbers with the ones of the three lowest electronic states of the cation (see Table 8). The peak positions of this extended series are listed in Table 7.

The vibronic structure of this spectrum demonstrates a change in geometry of the $\tilde{\mathrm{C}}^{+}$state with respect to the $\tilde{\mathrm{X}}$ neutral ground state. The same trend was observed for the $\tilde{\mathrm{C}}^{+}$state of $\mathrm{HC}_{3} \mathrm{~N}^{+}$by Baker and Turner [37].

Note that the origin of the $\tilde{\mathrm{D}}^{+} \leftarrow \tilde{\mathrm{X}}{ }^{1} \mathrm{~A}_{1}$ transition is not observed. Nevertheless, a very tentative value of $130160 \pm$ $500 \mathrm{~cm}^{-1}$ for the vertical ionization threshold can be derived from the maximum of the broad bump reached before the drop of the signal (see Fig. 6). In the PES spectrum of Bieri et al., which exhibits a different energy profile for this band, they peaked the maximum of the transition to the $\tilde{\mathrm{D}}^{+}$state at $131468 \mathrm{~cm}^{-1}$ [21]. 
Table 8: Experimental and calculated (in italics) vibrational wavenumbers of the electronic ground state of $\mathrm{CH}_{3} \mathrm{C}_{3} \mathrm{~N}$ and the four lowest electronic states of $\mathrm{CH}_{3} \mathrm{C}_{3} \mathrm{~N}^{+}$. All values are in $\mathrm{cm}^{-1}$ and error bars are given in parenthesis. When no unambiguous correlation between the neutral and cation normal mode can be drawn, the calculated value is replaced by a question mark.

\begin{tabular}{|c|c|c|c|c|c|c|c|c|}
\hline & \multirow[t]{2}{*}{$\tilde{\mathrm{X}}^{1} \mathrm{~A}_{1}$} & \multicolumn{2}{|c|}{$\tilde{\mathrm{X}}^{+2} \mathrm{E}$} & \multicolumn{2}{|c|}{$\tilde{\mathrm{A}}^{+2} \mathrm{~A}_{1}$} & \multicolumn{2}{|c|}{$\tilde{\mathrm{B}}^{+2} \mathrm{E}$} & \multirow{2}{*}{$\begin{array}{c}\tilde{\mathrm{C}}^{+} \\
\text {this work }\end{array}$} \\
\hline & & this work & literature & this work & literature & this work & literature & \\
\hline$\tilde{v}_{1}$ & $\begin{array}{c}2938.5^{a, c} \\
3023\end{array}$ & - & - & - & - & - & $>-$ & - \\
\hline$\tilde{v}_{2}$ & $\begin{array}{c}2271^{a, c} \\
2384\end{array}$ & $\begin{array}{c}2178(20) \\
2275\end{array}$ & $2100(80)^{g}$ & $2246(30)$ & $2332(30) ?^{h}$ & & - & - \\
\hline$\tilde{v}_{3}$ & $\begin{array}{c}2168^{a, c} \\
2252\end{array}$ & $\begin{array}{c}1933(30) \\
2018\end{array}$ & - & - & & 1987(30) & - & - \\
\hline$\tilde{v}_{4}$ & $\begin{array}{c}1373.5^{a, d} \\
1403\end{array}$ & $\begin{array}{c}\left(1381(30)^{f}\right) \\
?\end{array}$ & - & - & & - & - & - \\
\hline$\tilde{v}_{5}$ & $\begin{array}{c}1156^{a, c} \\
1174\end{array}$ & $\begin{array}{c}1228(20) \\
1224\end{array}$ & - & $1159(40)$ & - & $1132(20)$ & $\begin{array}{l}1100(80)^{g} \\
1105(30)^{h}\end{array}$ & - \\
\hline$\tilde{v}_{6}$ & $\begin{array}{c}642.5^{a, c} \\
670\end{array}$ & $\begin{array}{c}653(30) \\
680\end{array}$ & - & $655(30)$ & $\begin{array}{l}560(80)^{g} \\
545(30)^{h}\end{array}$ & $693(30)$ & $\begin{array}{l}700(80)^{g} \\
676(30)^{h}\end{array}$ & $705(40)$ \\
\hline$\tilde{v}_{7}$ & $\begin{array}{c}2987^{a} \\
3090\end{array}$ & - & & - & - & - & - & - \\
\hline$\tilde{v}_{8}$ & $\begin{array}{r}1445^{a} \\
1464\end{array}$ & $\left(1381(30)^{f}\right)$ & - & $1621(20)$ & - & - & - & $1586(40)$ \\
\hline$\tilde{v}_{9}$ & $\begin{array}{c}1030^{a} \\
1042\end{array}$ & $\begin{array}{c}1017(30) \\
?\end{array}$ & $930(80)^{g}$ & $926(30)$ & - & - & - & - \\
\hline$\tilde{v}_{10}$ & $\begin{array}{l}499^{a} \\
537\end{array}$ & $\begin{array}{l}- \\
?\end{array}$ & - & - & - & - & - & - \\
\hline$\tilde{v}_{11}$ & $\begin{array}{r}339^{a} \\
357\end{array}$ & $\begin{array}{c}224(30)^{i} \\
?\end{array}$ & - & $238(30)$ & - & $202(30)$ & - & - \\
\hline$\tilde{v}_{12}$ & $\begin{array}{c}144.75^{b, c} \\
146\end{array}$ & $\begin{array}{c}- \\
133\end{array}$ & - & - & - & $122(40)$ & - & - \\
\hline
\end{tabular}

${ }^{a}$ Ref. [13]. ${ }^{b}$ Ref. [15]. ${ }^{c}$ Average value of the R and $\mathrm{P}$ branch positions. ${ }^{d} 2 v_{4}$ band position divided by 2 . $^{e}$ wavenumbers corresponding to either $v_{1}$ or $v_{7}$ modes. ${ }^{f}$ wavenumbers corresponding to either $v_{4}$ or $v_{8}$ modes. ${ }^{g}$ From PES experiment of Ref. [21]. ${ }^{h}$ From EAS experiment of Ref. [24]. ${ }^{i}$ Derived from the $11^{2}$ band position. 
Table 7: Band wavenumbers and assignments of the $\tilde{\mathrm{C}}^{+} \leftarrow \tilde{\mathrm{X}}{ }^{1} \mathrm{~A}_{1}$ vibronic transitions observed in the TPES. All values are in $\mathrm{cm}^{-1}$.

\begin{tabular}{ccc} 
Wavenumber & Wavenumber $-I P\left(\tilde{\mathrm{C}}^{+}\right)^{a}$ & $\begin{array}{c}\text { Upper level } \\
\text { assignment }\end{array}$ \\
\hline 119390 & 0 & $0^{0}$ \\
120095 & 705 & $6^{1}$ \\
120976 & 1586 & $8^{1}$ \\
121628 & 2238 & $8^{1} 6^{1}$ \\
122318 & 2928 & $8^{2}$ \\
123083 & 3693 & $8^{2} 6^{1}$ \\
123864 & 4474 & $8^{3}$ \\
124536 & 5146 & $8^{3} 6^{1}$ \\
125176 & 5786 & $8^{4}$ \\
125975 & 6585 & $8^{4} 6^{1}$ \\
126507 & 7117 & $8^{5}$ \\
127225 & 7835 & $8^{5} 6^{1}$ \\
127982 & 8592 & $8^{6}$ \\
128793 & 9403 & $8^{6} 6^{1}$ \\
\hline
\end{tabular}

${ }^{a} \operatorname{IP}\left(\tilde{\mathrm{C}}^{+}\right)=119390 \mathrm{~cm}^{-1}$

\subsection{Dissociative ionization of cyanopropyne}

Mass spectra recorded at 12, 15.5 and $20 \mathrm{eV}$ are presented in Figs. 7 a), b) and c), respectively. The mass spectrum of Fig. 7 a) (at $12 \mathrm{eV}$ ) exhibits only two peaks corresponding to the $\mathrm{CH}_{3} \mathrm{C}_{3} \mathrm{~N}^{+}$parent ion $(m / q=65)$ and its natural ${ }^{13} \mathrm{C}$ isotopologue $(m / q=66)$. The mass spectrum of Fig. 7 b) (at $15.5 \mathrm{eV})$ already starts to show evidences for dissociative ionization with two main fragments at $m / q=38$ and $m / q=64$ and very weak signals at $m / q=15, m / q=28$ and $m / q=63$ (hardly visible on the scale of this spectrum, see spectrum of panel c) at $20 \mathrm{eV}$ ). The mass spectrum of Fig. 7 c) (at $20 \mathrm{eV}$ ) presents the same fragments and in addition $m / q=37$. All the other ion signals are due to ${ }^{13} \mathrm{C}$ isotopologues or impurities (see below).

Let us examine first the mass signals which are not directly relevant for the present study.

The signals at $m / q=18$ and $m / q=17$ in Figs. 7 b) and c) correspond to $\mathrm{H}_{2} \mathrm{O}$ and its $\mathrm{OH}$ dissociative ionization fragment since water was a residual by-product of the $\mathrm{CH}_{3} \mathrm{C}_{3} \mathrm{~N}$ synthesis.

Between masses 40 and 55, we observe residual impurities coming from other samples studied with the same experimental setup in the past. The masses observed at $m / q=44,50$ and 51 can be assigned without any ambiguity to $\mathrm{CD}_{3} \mathrm{CN}, \mathrm{CH}_{3} \mathrm{Cl}$ and $\mathrm{HC}_{3} \mathrm{~N}$, respectively, comparing the observed ion yields (not shown here) with earlier works $[39,40,1]$.

The mass spectrum of Fig. 7 b) exhibits a peak at $m / q=62$ which might be assigned to the $\mathrm{C}_{4} \mathrm{~N}^{+}$fragment at first sight. However, the appearance energy measured for this mass was lower $(\approx 12.1 \mathrm{eV})$ than the ones of $\mathrm{H}$ - and $\mathrm{H}_{2}$-loss channels (see below). We rather assign it to a dissociative ionization fragment of $\mathrm{CH}_{3} \mathrm{C}_{5} \mathrm{~N}$ traces, which had been studied during the same experimental beamtime. Indeed, the excitation of $\mathrm{CH}_{3} \mathrm{C}_{5} \mathrm{~N}$ at 15.5 $\mathrm{eV}$ produces a strong ion signal at $m / q=62$ corresponding to $\mathrm{C}_{4} \mathrm{~N}^{+}$(see mass spectrum in Appendix $\mathrm{C}$ ). No dissociative ion yield has been recorded for this molecule but the complete dis-

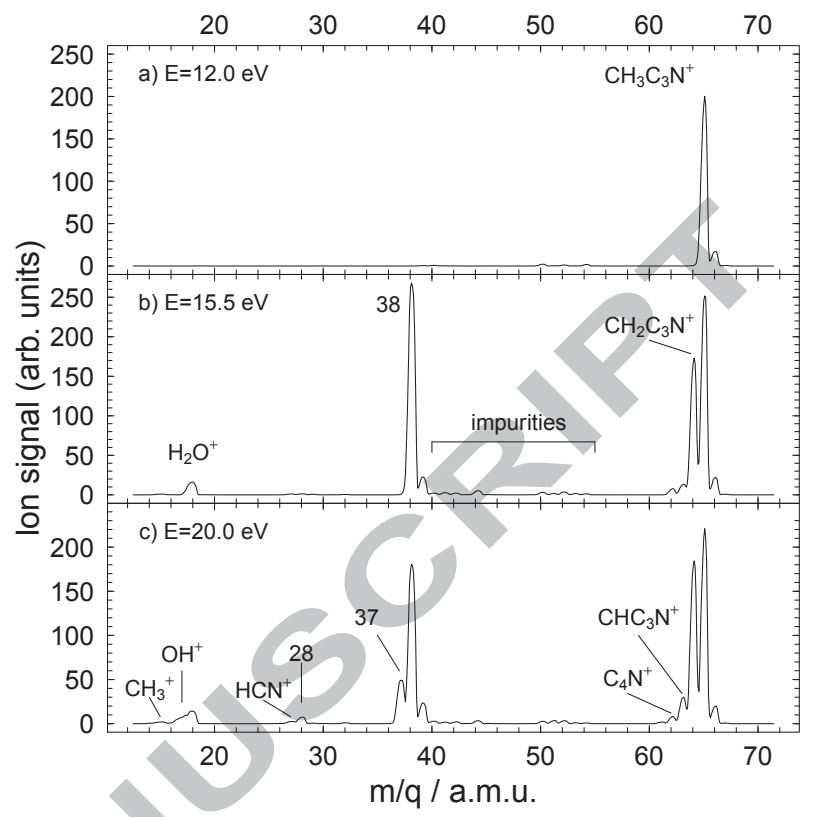

Figure 7: Mass spectra obtained with photon energies of a) $12 \mathrm{eV}$, b) $15.5 \mathrm{eV}$ and c) $20 \mathrm{eV}$.

sociative photoionization study of $\mathrm{CH}_{3} \mathrm{C}_{5} \mathrm{~N}$ will be investigated in details soon.

Finally, the signal observed at $m / q=27$ is attributed to photoionization of HCN by comparing the ion yield measured in this work with the one of Ref. [37]. The neutral HCN molecule responsible for this signal is suspected to be a product of either photolysis or dissociative photoionization of cyanopropyne.

During our experimental beamtime, we only measured the appearance energies of the fragments which are below $15.5 \mathrm{eV}$. Thus, the data corresponding to masses 64, 63, 38, 28 and 15 are discussed below and their corresponding ion yields are presented in Figs. 8 a) to e). The observed appearance energies are marked by arrows in these figures and summarized in Table 9. In this table, the experimental measurements are compared with the calculated thresholds which allows us to propose a corresponding dissociative ionization process for each fragment.

As mentioned in section 3, the calculated thresholds only give a rough idea of the corresponding appearance energies. For instance, the calculated ionization energy of $\mathrm{CH}_{3} \mathrm{C}_{3} \mathrm{~N}$ is $10.22 \mathrm{eV}$ whereas the experimental value is $10.77 \mathrm{eV}$ $\left(86872 \mathrm{~cm}^{-1}\right)$, which gives a discrepancy of $0.55 \mathrm{eV}$. One should also keep in mind that the calculations do not take into account the temperature dependence and the possible activation barrier of the dissociative channels, as explained in section 3 . Thus, we roughly estimate that the calculated thresholds are reasonably representative of the observed appearance energies within $1 \mathrm{eV}$.

In Table 9, one can see that the channels producing ions with $m / q=64$ and $m / q=63$ (seen in Fig. 8 a) and b)) are easily assigned to the $\mathrm{CH}_{2} \mathrm{C}_{3} \mathrm{~N}^{+}(\mathrm{S})+\mathrm{H}$ and $\mathrm{CHC}_{3} \mathrm{~N}^{+}(\mathrm{D})+\mathrm{H}_{2}$ dissociative channels and that the calculations are in good agreement 


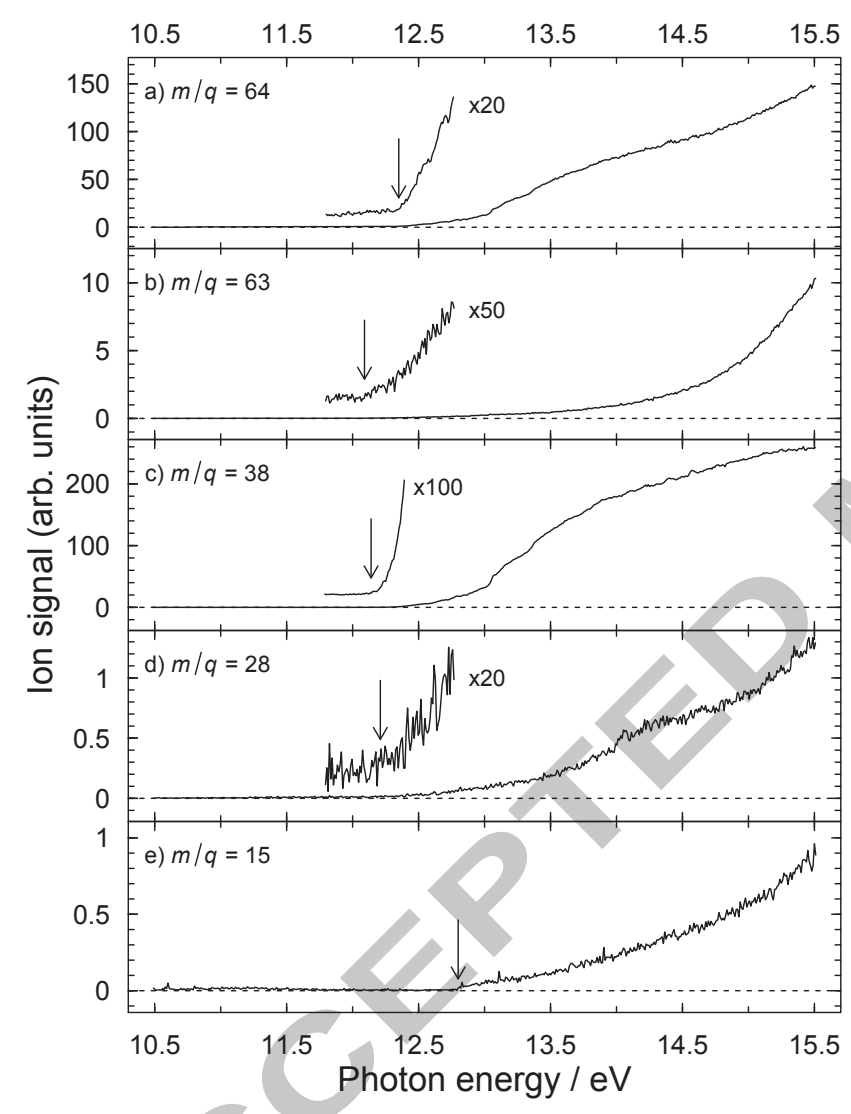

Figure 8: Fragment ion yields of the dissociative photoionization of $\mathrm{CH}_{3} \mathrm{C}_{3} \mathrm{~N}$. Note that the vertical scale is identical for all fragments. The arrows indicate the appearance energy of each fragment. See text for more details. with the observed appearance energies.

The appearance energy measured for $m / q=38$ (see Fig. 8 c)) is close to the calculated threshold for the $\mathrm{HC}_{3} \mathrm{H}^{+}(\mathrm{D})+$ $\mathrm{HCN}(\mathrm{S})$ channel. This channel is quite surprising and complex mechanisms have to be involved in the dissociative ionization processes to lead to these reorganised fragments. Similar molecular rearrangements have to be invoked to understand the $m / q=37$ fragment formation (production of $\mathrm{C}_{3} \mathrm{H}^{+}$, see Table 9). As mentioned above, the corresponding ion yield has not been measured but the mass spectra of Figs. 7 b) and c) allow to give lower and upper limit values: between 15.5 and $20.0 \mathrm{eV}$. Unfortunately, the calculated thresholds of the three possible channels lie in this range and we cannot conclude on the process responsible for this $\mathrm{C}_{3} \mathrm{H}^{+}$fragment.

Finally, the fragments at $m / q=28$ and 15 are the two minor products. The measured appearance energies are close to the threshold of the lowest dissociative channel calculated for these two masses and involving ion-pair formation $\left(\mathrm{HCNH}^{+}(\mathrm{S})+\right.$ $\mathrm{HC}_{3}{ }^{-}(\mathrm{S})$ and $\left.\mathrm{CH}_{3}^{+}(\mathrm{S})+\mathrm{C}_{3} \mathrm{~N}^{-}(\mathrm{S})\right)$. One can remark that the ion yields corresponding to the proposed ion-pair formations have weaker intensities by 1 or 2 order of magnitudes compared to the other fragments (see vertical scales of Fig. 8) which is consistent with the usual ion-pair formation efficiency. One could argue that the experimental appearance energy for $m / q=15$ is quite high with respect to the calculated one compared with the overall agreement for the other channels. However, ionpair potential curve minima are not located at the same equilibrium geometry as the ground state of the molecule [41]. Therefore, a photon excitation (which is a vertical excitation) brings the molecule in the Franck-Condon region of the ion-pair potential curve which is often higher than the ion-pair dissociative threshold. This could explain the consequent difference of $1.7 \mathrm{eV}$ observed between the experimental and calculated energies. In the case of the $m / q=28$ channel, the excess energy is only about $0.1 \mathrm{eV}$. A possible explanation is that the ion-pair dissociation process is different. Indeed, unlike in the $\mathrm{CH}_{3}^{+}+$ $\mathrm{C}_{3} \mathrm{~N}^{-}$channel which seems to proceed through a direct dissociation process, the $\mathrm{HCNH}^{+}+\mathrm{HC}_{3}{ }^{-}$channel necessitates an important atomic rearrangement probably involving intermediates which might be coupled to the ion-pair potential curve [41] leading to a near-threshold dissociation.

\section{Conclusion}

Photoionization spectroscopy of cyanopropyne has been investigated by TPES for the first time over a wide energy range at SOLEIL synchrotron facility thanks to the VUV tunability of the DESIRS beamline. New values of the ionization thresholds towards the four lowest electronic states of the cation have been measured with improved accuracy. The vibrationally-resolved spectra combined with DFT calculations bring new insights on the complex vibronic structure of $\mathrm{CH}_{3} \mathrm{C}_{3} \mathrm{~N}^{+}$. The DFT calculations performed in this work predict for the first time the geometry of the electronic ground state of the cation and account for the vibrational progression observed in our experimental spectrum. This geometry was found to be of $\mathrm{C}_{\mathrm{s}}$ symmetry due to a Jahn-Teller interaction. Higher resolved experiments should be 
Table 9: Calculated thresholds and experimental appearance energies of dissociative ionization channels of $\mathrm{CH}_{3} \mathrm{C}_{3} \mathrm{~N}$. The uncertainties of the experimental values are about $0.10 \mathrm{eV}$. (S) and (T) denote the singlet or triplet spin multiplicity of the fragments (the fragments are in doublet states when it is not specified). See text for more details.

\begin{tabular}{|c|c|c|c|}
\hline $\begin{array}{l}m / q \\
\text { / a.m.u. }\end{array}$ & channel & $\begin{array}{l}A E_{\text {calc }} \\
/ \mathrm{eV}\end{array}$ & $\begin{array}{l}A E_{\exp } \\
/ \mathrm{eV}\end{array}$ \\
\hline 64 & $\mathrm{CH}_{2} \mathrm{C}_{3} \mathrm{~N}^{+}(\mathrm{S})+\mathrm{H}$ & 12.7 & 12.35 \\
\hline 63 & $\begin{array}{l}\mathrm{CHC}_{3} \mathrm{~N}^{+}+\mathrm{H}_{2}(\mathrm{~S}) \\
\mathrm{CHC}_{3} \mathrm{~N}^{+}+2 \mathrm{H}\end{array}$ & $\begin{array}{l}12.6 \\
16.9\end{array}$ & 12.09 \\
\hline 38 & $\begin{array}{l}\mathrm{HC}_{3} \mathrm{H}^{+}+\mathrm{HCN}(\mathrm{S}) \\
\mathrm{HC}_{3} \mathrm{H}^{+}+\mathrm{HNC}(\mathrm{S}) \\
\mathrm{H}_{2} \mathrm{C}_{3}^{+}+\mathrm{HCN}(\mathrm{S}) \\
\mathrm{H}_{2} \mathrm{C}_{3}^{+}+\mathrm{HNC}(\mathrm{S})\end{array}$ & $\begin{array}{l}12.4 \\
13.0 \\
13.9 \\
14.5\end{array}$ & 12.14 \\
\hline 37 & $\begin{array}{l}\mathrm{HC}_{3}^{+}(\mathrm{S})+\mathrm{H}_{2} \mathrm{CN} \\
\mathrm{HC}_{3}^{+}(\mathrm{S})+\mathrm{HCNH} \\
\mathrm{HC}_{3}^{+}(\mathrm{S})+\mathrm{H}_{2}(\mathrm{~S})+\mathrm{CN}\end{array}$ & $\begin{array}{l}15.5 \\
16.1 \\
17.9\end{array}$ & $\begin{array}{l}a \\
-a\end{array}$ \\
\hline 28 & $\begin{array}{l}\mathrm{HCNH}^{+}(\mathrm{S})+\mathrm{HC}_{3}{ }^{-}(\mathrm{S}) \\
\mathrm{HCNH}^{+}(\mathrm{S})+\mathrm{HC}_{3} \\
\mathrm{H}_{2} \mathrm{CN}^{+}(\mathrm{T})+\mathrm{HC}_{3}{ }^{-}(\mathrm{T}) \\
\mathrm{HCNH}^{+}(\mathrm{T})+\mathrm{HC}_{3}-(\mathrm{T}) \\
\mathrm{H}_{2} \mathrm{CN}^{+}(\mathrm{T})+\mathrm{HC}_{3}\end{array}$ & $\begin{array}{l}12.1 \\
13.8 \\
16.8 \\
16.8 \\
18.6\end{array}$ & 12.21 \\
\hline 15 & $\begin{array}{l}\mathrm{CH}_{3}^{+}(\mathrm{S})+\mathrm{C}_{3} \mathrm{~N}^{-}(\mathrm{S}) \\
\mathrm{CH}_{3}^{+}(\mathrm{S})+\mathrm{C}_{3} \mathrm{~N} \\
\mathrm{CH}_{3}^{+}(\mathrm{T})+\mathrm{C}_{3} \mathrm{~N}^{-}(\mathrm{T}) \\
\mathrm{NH}^{+}+\mathrm{C}_{4} \mathrm{H}_{2}(\mathrm{~S}) \\
\mathrm{CH}_{3}^{+}(\mathrm{T})+\mathrm{C}_{3} \mathrm{~N}\end{array}$ & $\begin{array}{l}11.1 \\
15.4 \\
18.1 \\
18.7 \\
18.8\end{array}$ & 12.80 \\
\hline
\end{tabular}

${ }^{a}$ The corresponding ion yield was not measured in this work. From Fig. 7, a threshold is expected between 15.5 and $20 \mathrm{eV}$ which does not allow to draw any conclusion about the corresponding process. carried out to highlight a clear signature of this interaction. In the ground and the second excited electronic states $\left(\tilde{X}^{+2} \mathrm{E}\right.$ and $\tilde{\mathrm{B}}^{+}{ }^{2} \mathrm{E}$ ) of the cation, a spin-orbit coupling of non-negligible magnitude is also expected. Indeed, in the $\mathrm{HC}_{3} \mathrm{~N}^{+}$cation, a spin-orbit splitting of $44 \mathrm{~cm}^{-1}$ has been measured [42]. In $\mathrm{CH}_{3} \mathrm{C}_{3} \mathrm{~N}^{+}$, we can suspect a spin-orbit splitting of the same order of magnitude, slightly decreased by the off-axis $\mathrm{H}$ atoms $[43,44]$. Thus, higher-resolved spectra of the $\tilde{\mathrm{X}}^{+}{ }^{2} \mathrm{E} \leftarrow \tilde{\mathrm{X}}{ }^{1} \mathrm{~A}_{1}$ transition should exhibit a complex rovibronic structure due to the combination of the Jahn-Teller effect and spin-orbit coupling like in propyne [34, 36] and the 2-butyne [45] cations. Pulsed-field-ionization zero-kinetic-energy photoelectron spectroscopy would be perfectly suited for this purpose. In addition vibronic coupling between the $\tilde{\mathrm{A}}^{+}$and $\tilde{\mathrm{B}}^{+}$electronic states is expected from their vicinity. More sophisticated multiconfigurational $a b$ initio calculations of the excited electronic states of $\mathrm{CH}_{3} \mathrm{C}_{3} \mathrm{~N}^{+}$, such as CASSCF approaches, are required to deepen our understanding of this cation.

Appearance energies for the dissociative photoionization channels below $15.5 \mathrm{eV}$ have been measured for the first time and the proposed channels are guided by quantum chemical calculations. Interestingly, two channels tentatively associated with ion-pair formation $\left(\mathrm{CH}_{3}^{+}+\mathrm{C}_{3} \mathrm{~N}^{-}\right.$and $\left.\mathrm{HCNH}^{+}+\mathrm{C}_{3} \mathrm{H}^{-}\right)$ are observed through the detection of the positive ion fragment. Experiments combining the detection of the positive and negative ions in coïncidence would allow to definitely confirm these channels.

\section{Appendix A. Correlation between the normal modes of the neutral and cationic species}

The approximate correlation between the normal modes of the neutral species and of the cation in the $\mathrm{C}_{3 \mathrm{v}}$ and $\mathrm{C}_{\mathrm{s}}$ point groups, respectively, are presented in the following Table A.10. This correlation is derived using the SD matrix displayed in Fig. 2 and only the main contributions (SD matrix elements greater than 0.2) are taken into account.

\section{Appendix B. Calculated FC factors for the $\tilde{\mathbf{X}}^{+}{ }^{2} \mathbf{E} \leftarrow$ $\tilde{\mathbf{X}}{ }^{1} \mathbf{A}_{1}$ transition}

The FC factors used in the calculated TPES spectrum of Fig 4 are reported in the following Table.

\section{Appendix C. $\mathrm{CH}_{3} \mathrm{C}_{5} \mathrm{~N}$ mass spectra}

The mass spectra of Fig. C.9 have been recorded by photoexciting $\mathrm{CH}_{3} \mathrm{C}_{5} \mathrm{~N}$ at 12 and $15 \mathrm{eV}$. The peak at $m / q=89$ corresponds to the parent molecule $\left(\mathrm{CH}_{3} \mathrm{C}_{5} \mathrm{~N}\right)$ and all the other ones to fragments coming from dissociative photoionization or impurities. Fig. C.9 b) exhibits a very strong signal at $m / q=62$ which probably comes from the $\mathrm{CH}_{3} \mathrm{C}_{5} \mathrm{~N}+h v \rightarrow$ $\mathrm{CH}_{3} \mathrm{C}+\mathrm{C}_{4} \mathrm{~N}^{+}+e^{-}$channel. The $\mathrm{CH}_{3} \mathrm{C}_{5} \mathrm{~N}$ was present in the experiment of our $\mathrm{CH}_{3} \mathrm{C}_{3} \mathrm{~N}$ study as residual impurity. Thus, these mass spectra justify our argumentation about the observed $m / q=62$ signal. Note that the impurities at $m / q=44,50$ and 
Table A.10: Correlation between the normal modes of the ground states of $\mathrm{CH}_{3} \mathrm{C}_{3} \mathrm{~N}$ and $\mathrm{CH}_{3} \mathrm{C}_{3} \mathrm{~N}^{+}$.

cation normal mode neutral normal mode

\begin{tabular}{cc}
$\left(\mathrm{C}_{\mathrm{s}}\right)$ & $\left(\mathrm{C}_{3 \mathrm{v}}\right)$ \\
\hline$v_{1}^{+}$ & $v_{1} / v_{7}$ \\
$v_{2}^{+}$ & $v_{1} / v_{7}$ \\
$v_{3}^{+}$ & $v_{2}$ \\
$v_{4}^{+}$ & $v_{3}$ \\
$v_{5}^{+}$ & $v_{4} / v_{8}$ \\
$v_{6}^{+}$ & $v_{4} / v_{8}$ \\
$v_{7}^{+}$ & $v_{5}$ \\
$v_{8}^{+}$ & $v_{9}$ \\
$v_{9}^{+}$ & $v_{6}$ \\
$v_{10}^{+}$ & $v_{10}$ \\
$v_{11}^{+}$ & $v_{11}$ \\
$v_{12}^{+}$ & $v_{12}$ \\
$v_{13}^{+}$ & $v_{7}$ \\
$v_{14}^{+}$ & $v_{8} / v_{9}$ \\
$v_{15}^{+}$ & $v_{10}$ \\
$v_{16}^{+}$ & $v_{9} / v_{11}$ \\
$v_{17}^{+}$ & $v_{9} / v_{11}$ \\
$v_{18}^{+}$ & $v_{12}$ \\
\hline
\end{tabular}

Table B.11: Calculated wavenumbers with respect to $I P\left(\tilde{\mathrm{X}}^{+}\right)$and FC factors of the $\tilde{\mathrm{X}}^{+}{ }^{2} \mathrm{E} \leftarrow \tilde{\mathrm{X}}{ }^{1} \mathrm{~A}_{1}$ transition. All transitions are from the vibronic ground state of the neutral and only the transitions with a FC factor greater than 0.008 are reported.

\begin{tabular}{ccc}
$\begin{array}{c}\text { Upper level assignment } \\
\left(\mathrm{C}_{\mathrm{s}} \text { notation }\right)\end{array}$ & wavenumber $/ \mathrm{cm}^{-1}$ & $\mathrm{FC}$ factor \\
\hline $0^{0}$ & 0 & 0.4201 \\
$11^{1}$ & 346 & 0.0108 \\
$17^{2}$ & 478 & 0.0294 \\
$16^{1} 17^{1}$ & 679 & 0.0205 \\
$9^{1}$ & 680 & 0.0156 \\
$8^{1}$ & 913 & 0.0338 \\
$7^{1}$ & 1224 & 0.0097 \\
$5^{1}$ & 1413 & 0.0082 \\
$3^{1}$ & 2275 & 0.1745 \\
$3^{1} 17^{2}$ & 2753 & 0.0122 \\
$3^{1} 16^{1} 17^{1}$ & 2954 & 0.0085 \\
$3^{1} 9^{1}$ & 2954 & 0.0090 \\
$3^{1} 8^{1}$ & 3188 & 0.0134 \\
$3^{2}$ & 4550 & 0.0326 \\
\hline
\end{tabular}

51 detected in the $\mathrm{CH}_{3} \mathrm{C}_{3} \mathrm{~N}$ experiment (see section 4.2) are also observed in the present mass spectra recorded prior to the $\mathrm{CH}_{3} \mathrm{C}_{3} \mathrm{~N}$ photoionization study.

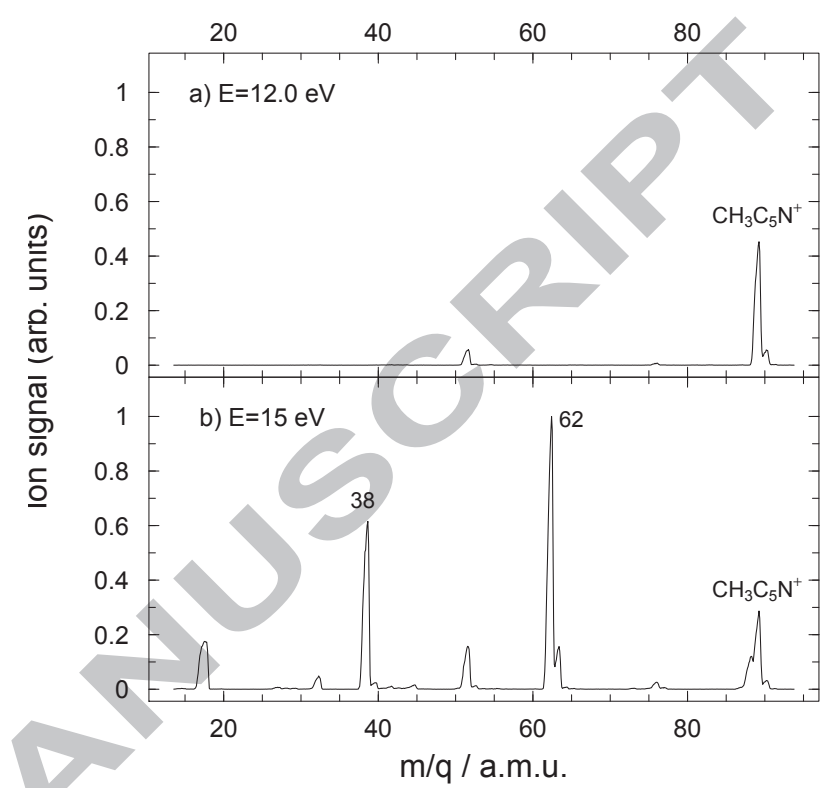

Figure C.9: Mass spectra obtained with photon energies of a) $12 \mathrm{eV}$ and b) 15 $\mathrm{eV}$ in the photoionization study of $\mathrm{CH}_{3} \mathrm{C}_{5} \mathrm{~N}$.

\section{Acknowledgments}

We acknowledge SOLEIL for provision of synchrotron radiation facilities. This work was performed on the DESIRS beamline under proposal number 20131102. J.-C. G. thanks the Centre National d'Etudes Spatiales (CNES) for financial support. The authors acknowledge the computating facility GMPCS of the LUMAT federation (FR LUMAT 2764). The authors would also like to thank J. Lievin for useful discussions.

\section{References}

\section{References}

[1] S. Leach, G. A. Garcia, A. Mahjoub, Y. Bénilan, N. Fray, M.-C. Gazeau, F. Gaie-Levrel, N. Champion, M. Schwell, Ionization photophysics and spectroscopy of cyanoacetylene, The Journal of Chemical Physics 140 (17) (2014) 174305. doi:http://dx.doi.org/10.1063/1.4871298.

[2] N. Broten, J. MacLeod, L. Avery, W. Irvine, B. Hoglund, P. Friberg, A. Hjalmarson, The detection of interstellar methylcyanoacetylene, The Astrophysical Journal Letters 276 (1984) L25-L29. doi:http://dx.doi.org/10.1086/184181.

[3] A. Belloche, H. S. P. Müller, K. M. Menten, P. Schilke, C. Comito, Complex organic molecules in the interstellar medium: IRAM $30 \mathrm{~m}$ line survey of Sagittarius B2(N) and (M), Astronomy \& Astrophysics 559 (2013) A47. doi:http://dx.doi.org/10.1051/0004-6361/201321096.

[4] F. J. Lovas, A. J. Remijan, J. M. Hollis, P. R. Jewell, L. E. Snyder, Hyperfine Structure Identification of Interstellar Cyanoallene toward TMC-1, The Astrophysical Journal Letters 637 (1) (2006) L37. doi:http://dx.doi.org/10.1086/500431. 
[5] M. Lattelais, F. Pauzat, Y. Ellinger, C. Ceccarelli, Interstellar Complex Organic Molecules and the Minimum Energy Principle, The Astrophysical Journal Letters 696 (2) (2009) L133. doi:http://dx.doi.org/10.1088/0004-637X/696/2/L133.

[6] W. R. Thompson, T. J. Henry, J. M. Schwartz, B. N. Khare, C. Sagan, Plasma discharge in $\mathrm{N}_{2}+\mathrm{CH}_{4}$ at low pressures: Experimental results and applications to Titan, Icarus 90 (1) (1991) 57-73. doi:http://dx.doi.org/10.1016/0019-1035(91)90068-5.

[7] P. Coll, D. Coscia, N. Smith, M.-C. Gazeau, S. I. Ramrez, G. Cernogora, G. Israël, F. Raulin, Experimental laboratory simulation of Titans atmosphere: aerosols and gas phase, Planetary and Space Science 47 (1011) (1999) 1331-1340. doi:http://dx.doi.org/10.1016/S0032-0633(99)000549

[8] G. J. Molina-Cuberos, K. Schwingenschuh, J. J. López-Moreno, R. Rodrigo, L. M. Lara, V. Anicich, Nitriles produced by ion chemistry in the lower ionosphere of Titan, Journal of Geophysical Research: Planets 107 (E11) (2002) 9-11. doi:http://dx.doi.org/10.1029/2000JE001480.

[9] V. Vuitton, R. V. Yelle, M. J. McEwan, Ion chemistry and N-containing molecules in Titan's upper atmosphere, Icarus 191 (2) (2007) 722-742. doi:http://dx.doi.org/10.1016/j.icarus.2007.06.023.

[10] R. I. Kaiser, N. Balucani, The Formation of Nitriles in Hydrocarbon-Rich Atmospheres of Planets and Their Satellites: Laboratory Investigations by the Crossed Molecular Beam Technique, Accounts of Chemical Research 34 (9) (2001) 699-706. doi:http://dx.doi.org/10.1021/ar000112v.

[11] N. Balucani, O. Asvany, Y. Osamura, L. C. L. Huang, Y. T. Lee, R. I. Kaiser, Laboratory investigation on the formation of unsaturated nitriles in Titans atmosphere, Planetary and Space Science 48 (5) (2000) 447462. doi:http://dx.doi.org/10.1016/S0032-0633(00)00018-0.

[12] L. C. L. Huang, N. Balucani, Y. T. Lee, R. I. Kaiser, Y. Osamura, Crossed beam reaction of the cyano radical, $\mathrm{CN}\left(\mathrm{X}^{2} \Sigma^{+}\right)$, with methylacetylene, $\mathrm{CH}_{3} \mathrm{CCH}\left(\mathrm{X}^{1} \mathrm{~A}^{1}\right)$ : Observation of cyanopropyne, $\mathrm{CH}_{3} \mathrm{CCCN}\left(\mathrm{X}^{1} \mathrm{~A}^{1}\right)$, and cyanoallene, $\mathrm{H}_{2} \mathrm{CCCHCN}\left(\mathrm{X}^{1} \mathrm{~A}^{\prime}\right)$, The Journal of Chemical Physics 111 (7) (1999) 2857-2860. doi:http://dx.doi.org/10.1063/1.479567.

[13] R. Tubino, G. Dellepiane, G. Zerbi, Vibrational Spectrum and VibroRotational Analysis of Cyanopropyne, The Journal of Chemical Physics 50 (2) (1969) 621-627. doi:http://dx.doi.org/10.1063/1.1671109.

[14] F. Cerceau, F. Raulin, R. Courtin, D. Gautier, Infrared spectra of gaseous mononitriles: Application to the atmosphere of Titan, Icarus 62 (2) (1985) 207-220. doi:http://dx.doi.org/10.1016/0019-1035(85)90118-6.

[15] M. Khlifi, F. Raulin, Infrared intensifies and frequencies of 2 butynenitrfie: Application to the atmosphere of Titan, Spectrochimica Acta Part A: Molecular Spectroscopy 47 (2) (1991) 171-176. doi:http://dx.doi.org/10.1016/0584-8539(91)80088-Z.

[16] J. Sheridan, L. F. Thomas, Microwave Spectrum of Methyl-Cyanoacetylene, Nature 174 (4434) (1954) 798. doi:http://dx.doi.org/10.1038/174798a0.

[17] A. Moïses, D. Boucher, J. Burie, J. Demaison, A. Dubrulle, Millimeterwave spectrum of methylcyanoacetylene, Journal of Molecular Spectroscopy 92 (2) (1982) 497-498. doi:http://dx.doi.org/10.1016/00222852(82)90118-7.

[18] M. Bester, M. Tanimoto, B. Vowinkel, G. Winnewisser, K. Yamada, Rotational spectrum of methylcyanoacetylene. A new millimiter wave spectrometer, Zeitschrift Für Naturforschung Section A-A Journal Of Physical Sciences 38 (1) (1983) 64-67.

[19] K. M. T. Yamada, M. Bester, M. Tanimoto, G. Winnewisser, Pure rotational spectrum of cyanopropyne in the v12 $=1$ vibrational state, Journal of Molecular Spectroscopy 126 (1) (1987) 118-128. doi:http://dx.doi.org/10.1016/0022-2852(87)90082-8.

[20] P. Bruston, H. Poncet, F. Raulin, C. Cossart-Magos, R. Courtin, UV spectroscopy of Titan's atmosphere, planetary organic chemistry, and prebiological synthesis: I. Absorption spectra of gaseous propynenitrile and 2-butynenitrile in the 185- to 250-nm region, Icarus 78 (1) (1989) 38-53. doi:http://dx.doi.org/10.1016/0019-1035(89)90068-7.

[21] G. Bieri, E. Heilbronner, V. Hornung, E. Kloster-Jensen, J. P. Maier, F. Thommen, W. von Niessen, Electronic states of substituted haloacetylene and cyanoacetylene radical cations, Chemical Physics 36 (1) (1979) 1-14. doi:http://dx.doi.org/10.1016/0301-0104(79)85099-5.

[22] L. Åsbrink, W. von Niessen, G. Bieri, 30.4-nm He(II) Photoelectron spectra of organic molecules: Part II. Aza-compounds $(\mathrm{C}, \mathrm{H}, \mathrm{N}$,$) , Journal of$ Electron Spectroscopy and Related Phenomena 21 (1) (1980) 93-101. doi:http://dx.doi.org/10.1016/0368-2048(80)85039-0.
[23] R. Kuhn, J. P. Maier, F. Thommen, Photoelectron-photon coincidence studies of the A and B excited electronic states of X-CC-CN+, X = $\mathrm{CH} 3, \mathrm{CD} 3, \mathrm{Cl}, \mathrm{Br}$, I, Journal of Electron Spectroscopy and Related Phenomena 34 (3) (1984) 253-260. doi:http://dx.doi.org/10.1016/03682048(84)80069-9.

[24] J. Fulara, S. Leutwyler, J. P. Maier, U. Spittel, Electronic absorption spectra of cyanogen cation $\left(\mathrm{NCCN}^{+}\right)$, cyanoacetylene cation $\left(\mathrm{HCCCN}^{+}\right)$, and methylcyanoacetylene cation $\left(\mathrm{MeCCCN}^{+}\right)$in neon matrixes, The Journal of Physical Chemistry 89 (15) (1985) 3190-3193. doi:http://dx.doi.org/10.1021/j100261a004.

[25] W. V. Niessen, L. S. Cederbaum, J. Schirmer, G. H. F. Diercksen, W. P. Kraemer, Ionization energies of some molecules found in interstellar clouds calculated by a green's function method, Journal of Electron Spectroscopy and Related Phenomena 28 (1) (1982) 45-78. doi:http://dx.doi.org/10.1016/0368-2048(82)80016-9.

[26] K. Siam, M. Dakkouri, J. D. Ewbank, L. Schäfer, Ab initio calculations of structural features not easily amenable to experiment: Part 68. Structural trends in some substituted nitriles and acetylenes, Journal of Molecular Structure: \{THEOCHEM\} 204 (0) (1990) 291-300. doi:http://dx.doi.org/10.1016/0166-1280(90)85081-W.

[27] V. Moliner, J. Añdrés, A. Arnau, E. Silla, I. Tuñón, Rotational constants and dipole moments of interstellar polyynes: a comparative $\{$ MP2 $\}$ and density functional (BP86) study, Chemical Physics 206 (12) (1996) 5761. doi:http://dx.doi.org/10.1016/0301-0104(96)00007-9.

[28] D. Strübing, H. Neumann, S. Klaus, S. Hübner, M. Beller, A facile and efficient synthesis of enyne-reaction precursors by multicomponent reactions, Tetrahedron 61 (48) (2005) 11333-11344. doi:http://dx.doi.org/10.1016/j.tet.2005.09.097.

[29] L. Nahon, N. de Oliveira, G. A. Garcia, J.-F. Gil, B. Pilette, O. Marcouillé, B. Lagarde, F. Polack, DESIRS: a state-of-the-art VUV beamline featuring high resolution and variable polarization for spectroscopy and dichroism at SOLEIL, Journal of Synchrotron Radiation 19 (4) (2012) 508-520. doi:http://dx.doi.org/10.1107/S0909049512010588.

[30] B. Mercier, M. Compin, C. Prevost, G. Bellec, R. Thissen, O. Dutuit, L. Nahon, Experimental and theoretical study of a differentially pumped absorption gas cell used as a low energy-pass filter in the vacuum ultraviolet photon energy range, Journal of Vacuum Science \& Technology A 18 (5) (2000) 2533-2541. doi:http://dx.doi.org/10.1116/1.1288196.

[31] C. Alcaraz, C. Nicolas, R. Thissen, J. Zabka, O. Dutuit, ${ }^{15} \mathrm{~N}^{+}+\mathrm{CD}_{4}$ and $\mathrm{O}^{+}+{ }^{13} \mathrm{CO}_{2}$ State-Selected IonMolecule Reactions Relevant to the Chemistry of Planetary Ionospheres, The Journal of Physical Chemistry A 108 (45) (2004) 9998-10009. doi:http://dx.doi.org/10.1021/jp0477755.

[32] M. J. Frisch, G. W. Trucks, H. B. Schlegel, G. E. Scuseria, M. A. Robb, J. R. Cheeseman, G. Scalmani, V. Barone, B. Mennucci, G. A. Petersson, H. Nakatsuji, M. Caricato, X. Li, H. P. Hratchian, A. F. Izmaylov, J. Bloino, G. Zheng, J. L. Sonnenberg, M. Hada, M. Ehara, K. Toyota, R. Fukuda, J. Hasegawa, M. Ishida, T. Nakajima, Y. Honda, O. Kitao, H. Nakai, T. Vreven, J. A. Montgomery Jr., J. E. Peralta, F. Ogliaro, M. Bearpark, J. J. Heyd, E. Brothers, K. N. Kudin, V. N. Staroverov, R. Kobayashi, J. Normand, K. Raghavachari, A. Rendell, J. C. Burant, S. S. Iyengar, J. Tomasi, M. Cossi, N. Rega, J. M. Millam, M. Klene, J. E. Knox, J. B. Cross, V. Bakken, C. Adamo, J. Jaramillo, R. Gomperts, R. E. Stratmann, O. Yazyev, A. J. Austin, R. Cammi, C. Pomelli, J. W. Ochterski, R. L. Martin, K. Morokuma, V. G. Zakrzewski, G. A. Voth, P. Salvador, J. J. Dannenberg, S. Dapprich, A. D. Daniels, O. Farkas, J. B. Foresman, J. V. Ortiz, J. Cioslowski, D. J. Fox, Gaussian 09 Revision D.01.

[33] F. A. Hamprecht, A. J. Cohen, D. J. Tozer, N. C. Handy, Development and assessment of new exchange-correlation functionals, The Journal of Chemical Physics 109 (1998) 6264-6271. doi:http://dx.doi.org/10.1063/1.477267.

[34] S. Marquez, J. Dillon, D. R. Yarkony, On the Photoionization Spectrum of Propyne: A Fully ab Initio Simulation of the Low-Energy Spectrum Including the JahnTeller Effect and the SpinOrbit Interaction, The Journal of Physical Chemistry A 117 (46) (2013) 12002-12010. doi:http://dx.doi.org/10.1021/jp403745q.

[35] V. Barone, J. Bloino, M. Biczysko, F. Santoro, Fully Integrated Approach to Compute Vibrationally Resolved Optical Spectra: From Small Molecules to Macrosystems, Journal of Chemical Theory and Computation 5 (2009) 540-554. doi:http://dx.doi.org/10.1021/ct8004744.

[36] X. Xing, M.-K. Bahng, B. Reed, C. S. Lam, K.-C. Lau, C. Y. Ng, Rovi- 
brationally selected and resolved pulsed field ionization-photoelectron study of propyne: Ionization energy and spin-orbit interaction in propyne cation, The Journal of Chemical Physics 128 (9) (2008) -. doi:http://dx.doi.org/10.1063/1.2836429.

[37] C. Baker, D. W. Turner, High resolution molecular photelectron spectroscopy. III. Acetylenes and aza-acetylenes, Proceedings of the Royal Society of London. Series A. Mathematical and Physical Sciences 308 (1492) (1968) 19-37. doi:http://dx.doi.org/10.1098/rspa.1968.0205.

[38] L. A. V. Mendes, S. Boyé-Péronne, U. Jacovella, J. Liéven,

D. Gauyacq, Rydberg states of cyanoacetylene investigated by $(3+1)$ REMPI spectroscopy in the 77,000 $90,000 \mathrm{~cm}^{-1}$ energy range, Molecular Physics 110 (2012) 2829-2842. doi:http://dx.doi.org/10.1080/00268976.2012.706327.

[39] M. Schwell, H.-W. Jochims, H. Baumgärtel, S. Leach, \{VUV\} photophysics of acetonitrile: Fragmentation, fluorescence and ionization in the $722 \mathrm{eV}$ region, Chemical Physics 344 (12) (2008) 164-175. doi:http://dx.doi.org/10.1016/j.chemphys.2007.12.011.

[40] R. Locht, B. Leyh, A. Hoxha, D. Dehareng, K. Hottmann, H. W. Jochims, H. Baumgärtel, About the photoionization of methyl chloride. A threshold photoelectron spectroscopic and photoionization mass spectrometric investigation, Chem. Phys. 272 (2001) 293-313. doi:http://dx.doi.org/10.1016/S0301-0104(01)00466-9.

[41] A. G. Suits, J. W. Hepburn, Ion pair dissociation: Spectroscopy and dynamics., Annual Review of Physical Chemistry 57 (2006) 431-465. doi:http://dx.doi.org/10.1146/annurev.physchem.56.092503.141209.

[42] A PFI-ZEKE study of $\mathrm{HC}_{3} \mathrm{~N}$ will be presented in a forthcoming publication by B. Gans, N. Lamarre, M. Broquier, C. Alcaraz and S. BoyéPéronne.

[43] D. S. McClure, Spin-orbit interaction in aromatic molecules, The Journal of Chemical Physics 20 (1952) 682-686. doi:http://dx.doi.org/10.1063/1.1700516.

[44] G. Herzberg, Molecular spectra and molecular structure III. Electronic spectra and electronic structure of polyatomic molecules., Van Nostrand Reinhold, 1966.

[45] U. Jacovella, B. Gans, F. Merkt, Internal rotation, spin-orbit coupling, and low-frequency vibrations in the $\tilde{\mathrm{X}}^{2} \mathrm{E}$ ground state of $\mathrm{CH}_{3}-\mathrm{CC}-\mathrm{CH}_{3}^{+}$and $\mathrm{CD}_{3}$-CC-CD ${ }_{3}^{+}$, Molecular Physics (2015) (just accepted). 


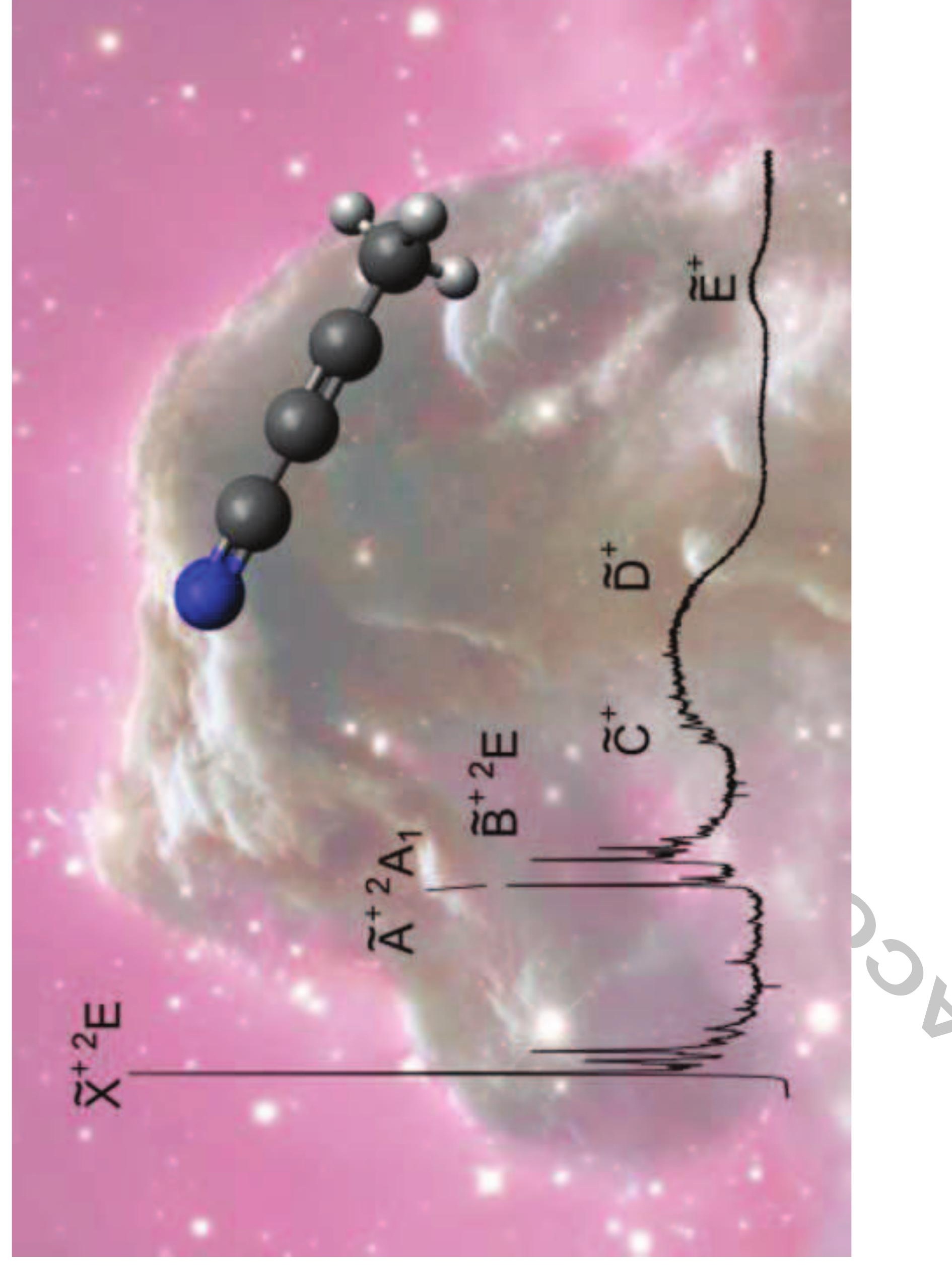




\section{$\underline{\text { Highlights }}$}

- Threshold photoelectron spectrum of cyanopropyne has been recorded for the first time between 86000 and $180000 \mathrm{~cm}^{-1}$.

- Analysis of the vibronic structure of the four lowest electronic states of the cyanopropyne cation has been performed.

- We report on the first observation of the dissociative photoionization channels below $120000 \mathrm{~cm}^{-1}$. 